\title{
WAGE AND PRODUCTIVITY DISPERSION IN U.S. MANUFACTURING: THE ROLE OF COMPUTER INVESTMENT
}

\author{
Timothy Dunne \\ Lucia Foster \\ John Haltiwanger \\ Kenneth Troske \\ Working Paper 7465 \\ http://www.nber.org/papers/w7465
NATIONAL BUREAU OF ECONOMIC RESEARCH 1050 Massachusetts Avenue
Cambridge, MA 02138 \\ January 2000
}

We would like to thank Robert Topel, Andrew Hildreth and seminar participants at Carnegie-Mellon, the Federal Reserve Bank of Kansas City, and UCLA for helpful comments. All opinions, findings, and conclusions expressed herein are those of the authors and do not in any way reflect the views of the U.S. Census Bureau or the National Bureau of Economic Research. The data used in this article were collected under the provisions of Title 13 U.S. Code and are only available at the Center for Economic Studies, U.S. Census Bureau. To obtain access to these data, contact Chief, Center for Economic Studies, U.S. Census Bureau, RM 21 1/WPII, Washington, D.C. 20233.

(C) 2000 by Timothy Dunne, Lucia Foster, John Haltiwanger, and Kenneth Troske. All rights reserved. Short sections of text, not to exceed two paragraphs, may be quoted without explicit permission provided that full credit, including $(\mathrm{C}$ notice, is given to the source. 
Wage and Productivity Dispersion in U.S. Manufacturing: The Role of Computer Investment Timothy Dunne, Lucia Foster, John Haltiwanger, and Kenneth Troske

NBER Working Paper No. 7465

January 2000

JEL No. J3, O3

\section{$\underline{\text { ABSTRACT }}$}

By exploiting establishment-level data, this paper sheds new light on the source of the changes in the structure of production, wages, and employment that have occurred over the last several decades. Based on theoretical work by Caselli (1999) and Kremer and Maskin (1996), we focus on investigating the following two related hypotheses. The first hypothesis is that the channel through which skill biased technical change works through the economy is via changes in the dispersion in wages and productivity across establishments. The second is that the increased dispersion in wages and productivity across establishments is linked to differential rates of technological adoption across establishments. Our findings are supportive of these hypotheses. Specifically, we find that (1) the between plant component of wage dispersion is a growing part of total wage dispersion, (2) much of the between plant increase in dispersion is within industries, (3) the between plant measures of wage and productivity dispersion have increased substantially over the last few decades, and (4) a substantial fraction of the rising dispersion in wages and productivity is accounted for by increasing wage and productivity differentials across high and low computer investment per worker plants and high and low capital intensity plants.

Timothy Dunne

Department of Economics

University of Oklahoma

Norman, OK 73019

tdunne@ou.edu

Lucia Foster

Center for Economic Studies

Bureau of the Census

Washington, D.C. 20233

lfoster@ces.census.gov
John Haltiwanger

Department of Economics

University of Maryland

College Park, MD 20742

and NBER

halt@cyclops.umd.edu

Kenneth R. Troske

Department of Economics

University of Missouri

Columbia, MO 65211

troskek@missouri.edu 


\section{Introduction}

Striking changes in the structure of production, wages, and employment have occurred over the last several decades. The introduction of computers and, more generally, advanced technologies into the workplace is widely viewed as one of the major factors underlying these changes. In particular, the role of advanced technology and computers has been closely linked to the rising inequality of worker wages. One hypothesis is that the introduction of advanced technologies and/or computers has led to a rising demand for skilled workers which, in turn, has led to a rise in the wages of skilled workers relative to unskilled workers. Competing hypotheses concerning the source of rising wage inequality include shifts in product demand and changes in institutional factors such as the decline of unions and changes in pay norms.

This paper attempts to shed new light on the source of these changes by exploiting establishment-level data to investigate the relationship between the dispersion of wages and the dispersion of productivity across establishments. The focus on between establishment dispersion in wages and productivity is a novel feature of our approach and analysis. This focus is motivated by recent theoretical work by Caselli (1999) and Kremer and Maskin (1996) which links the hypothesis of skill biased technical change to predictions regarding changes in wage and productivity dispersion across establishments. In principle, the rise in demand for skilled workers driven by skill biased technical change could be a within establishment phenomenon. That is, it may have been that the typical establishment experienced technological change that yielded a rising demand for skilled workers. Accordingly, the rising wage dispersion and/or any skill mix changes observed would be exhibited in the typical or average establishment. In contrast, the models of Caselli (1999) and Kremer and Maskin (1996) yield predictions that the skill biased technical change will be associated with greater dispersion in wages and productivity 
across establishments. This greater dispersion arises from the predictions of greater segregation in the labor market across establishments as well as related predictions about correlations between changes in wages and productivity across establishments with observable indicators of technology adoption across establishments. For example, the Caselli model suggests that changes in wage and productivity dispersion across establishments resulting from a skill-biased technical change (in this case the information technological revolution) should be related to changes in the distribution of capital in general and computers in particular across establishments. Our use of establishment-level data provides a basis for evaluating the relevance and validity of these predictions that focus on between establishment changes. In investigating this between establishment channel, we also provide another vantage point for evaluating the overall hypothesis of skill biased technical change relative to alternative hypotheses of changes in the structure of wages, productivity, and the workforce.

Our paper can also be viewed as helping to connect various strands of the literature studying wages, productivity, and computers. For example, many recent studies have sought to understand either the relationship between computers and wages (e.g., Krueger (1993), Doms, Dunne, and Troske (1997), Autor, Katz, and Krueger (1998)) or, alternatively, computers and productivity (e.g., Oliner and Sichel (1994), Greenan and Mairesse (1996), Siegel (1997) and Bresnahan, Brynjolfsson, and Hitt (1998)). One of our main objectives is to investigate these relationships simultaneously.

In a related manner, our analysis builds upon the parallel but separate literatures that exploit plant-level data to study the behavior of wages and productivity. Work by Davis and Haltiwanger (1991) has shown that the overall increase in wage inequality between workers is 
closely tied to an increase in the dispersion of wages between establishments. ${ }^{1,2}$ Further, much

of the latter change is a within-industry phenomenon so that the full exploration of these

differences requires plant-level data as opposed to industry-level data. This finding that the most important component of rising wage inequality is between-plant but within-industry suggests that the increase in relative demand for skilled workers is not due to a simple shift in product demand across industries. ${ }^{3}$ Related work on the determinants of plant-level wages (e.g., Doms, Dunne and Troske (1997)) finds that differences in the use and adoption of advanced technology is an important correlate of differences in the mix of workers and wages among plants within industries.

1 The variance decomposition of the total variance of wages into between and within plant components used in this paper draws heavily on the methodology from Davis and Haltiwanger (1991) (hereafter DH). The value-added of the results in this paper on this between/within decomposition of wage dispersion are twofold. First, we use a more comprehensive data set that permits inclusion of auxiliary establishments (e.g., central administrative offices, research facilities and warehouses) while $\mathrm{DH}$ were forced to generate adjustments for their nonproduction worker statistics to account for the contribution of auxiliary establishments. Second, the decomposition here considers the period 1977-92 while DH considered the period 1973-86. In addition, DH did not explore the related changes in the dispersion of productivity nor did they investigate the role of computers in accounting for changes in the wage and productivity dispersion.

2 Both the earlier and current work focus on manufacturing. However, as shown in section IV, the rising inequality for all workers is closely mimicked by rising inequality for workers in manufacturing. These findings suggest that although our plant-level analysis is confined to manufacturing, it likely has wide applicability. The restriction to manufacturing is dictated by data limitations. Only for manufacturing do we have the ability to investigate the link between productivity, wages and establishment-characteristics like capital intensity and computers per worker in a comprehensive, integrated manner for an extended period of time.

3 This inference is based on the presumption that product demand shifts would be related to between industry changes. This, of course, depends upon among other things the level of industry disaggregation. We consider this issue in the analysis that follows. 
Along these same lines, Baily, Hulten and Campbell (1992) and Olley and Pakes (1996) show that there is tremendous within-industry variation in productivity across plants. Further, they demonstrate that much of the increase in aggregate (industry-level) productivity is associated with the reallocation of resources across plants from less productive to more productive plants within the same industry. Unlike with wages, however, there has been little analysis of changes in the dispersion of productivity over time and little analysis of the role of advanced technology and computers in accounting for the observed differences in productivity across plants. ${ }^{4}$

The paper proceeds as follows. In Section II, we briefly outline both the Caselli (1999) and Kremer-Maskin (1996) models as well as present the implications of these models that are most relevant for our analysis. In Section III we decompose the total dispersion in hourly wages into within and between components over the $1975-92$ period. We find that virtually the entire increase in overall dispersion in hourly wages for U.S. manufacturing workers from 1975-92 is accounted for by the between-plant components. This result is quite important as it is at the core of the theories we are investigating.

In Section IV we examine the links between productivity and wages. At the aggregate level, we find that both the between-plant dispersion of wages and productivity increased markedly over the $1975-93$ period. At the plant level, we find that wages and productivity are strongly positively correlated in both levels and changes. Finally, we report that industries with large changes in the dispersion of wages across plants also exhibit large changes in the dispersion

${ }^{4}$ One exception is the work of Dwyer (1995) who examines the relationship between productivity and wage dispersion for the textile industry. He finds that plants in the textile industry with higher than average total factor productivity residuals also pay higher than average wages. 
of productivity across plants. Putting these results together with the results in Section III suggests that the changes in dispersion in both productivity and wages are closely linked.

In Section $\mathrm{V}$ we investigate these relationships by examining the role of observable and unobservable plant characteristics in accounting for the differences across plants in wages and labor productivity. The observable characteristics we consider include detailed industry controls, controls for the size and organizational structure of the establishment, measures of capital intensity, and computer investment per worker. We use this information to quantify the contribution of: (i) changes in the distribution of observable plant characteristics; (ii) changes in the wage and productivity differentials associated with these observable characteristics; and (iii) changes in unobserved factors; to changes in wage and productivity dispersion over time. We find that a large percentage of the observed changes in the dispersion of wages and productivity are accounted for by changes in the differentials associated with being a capital intensive or computer intensive plant. Section VI summarizes the main findings and provides an interpretation in terms of the alternative theoretical models under discussion.

\section{Review of Theoretical Literature}

The two theoretical papers that form the basis for our analysis are the papers by Caselli (1999) and Kremer and Maskin (1996). In this section we briefly outline the two models and present the most relevant predictions of the models.

Caselli (1999) models the effect of a technical revolution on the dispersion of wages and productivity. In the Caselli model a technology is a matching of workers of type $i$ who have the appropriate set of skills to operate machines of type $i$. An important feature of this technology assumption for our purposes is that workers are completely segregated by skill across plants. A 
technological revolution occurs with the development of a new type of machine. ${ }^{5}$ Examples of new types of machines mentioned by Caselli are the assembly line, the steam engine, and information technologies or computers. A revolution is skill biased if the skills required to operate the new machine are more costly for the workers to acquire than existing skills. ${ }^{6}$ Therefore, when a skill-biased revolution occurs, high skilled workers will be the first to use the new machines since it is less costly for them to acquire the new skills (this is the definition of high skilled in the model). Low skilled workers will continue to use the old machines. The model predicts that following a skill-biased technical revolution, because technologies have diminishing marginal returns and both types of machines must have the same rate of return in equilibrium, high skilled workers will work with more productive capital and with a greater amount of capital. Thus, plants that employ high skilled workers will have a higher capital-labor ratio.

This model has three implications that are relevant for our analysis. First, a skill-biased technical revolution leads to an increase in the dispersion of wages across plants. ${ }^{7}$ Since more skilled workers are using more capital and better capital relative to less skilled workers, their relative wages must increase, increasing the overall dispersion of wages across plants. Second, a skill-biased technical revolution also leads to an increase in the dispersion of productivity across plants. Skilled workers are using more and better machines. Therefore, their productivity,

\footnotetext{
${ }^{5}$ This is in contrast to an innovation which occurs when an improvement is made on an existing machine.

${ }^{6}$ A revolution is "deskilling" if the new skills required to operate the new machine are less costly to acquire than existing skills.

${ }^{7}$ Whether this increase in relative wages persists depends on a number of factors outlined in Caselli (1999).
} 
measured as either output per worker or output per hour worked, will rise relative to workers using the old machines, increasing the dispersion of productivity across plants. Third, the relative increases in wages and productivity should be associated with increases in capital in general at the plants that have adopted the new technology and, in the case of the information technological revolution, increases in computers or information technology equipment in particular.

Kremer and Maskin (1996) also provide a theoretical structure for our empirical analysis. Their model can account for the simultaneous existence of increased wage inequality and increased segregation of workers of different skill levels into different plants. These forces are set in motion by changes in the skill distribution, which can be due to a skill-biased technical change, but need not be. The main features of their model are imperfect substitution among workers of different skills, complementary tasks within a plant, differences in worker skill effects which vary by task, and an exogenous distribution of worker skills. Intuitively, there are two competing forces at work in determining the equilibrium matching patterns at plants. The asymmetry of tasks in the production function favors cross-matching (less segregation) but the complementarity between tasks favors self-matching (more segregation). Unequally skilled workers will be cross-matched up to the point in which the differences in skills is so great that the second effect overwhelms the first and the plant moves to self-matching. With a diffuse skill distribution, an increase in the mean skill-level exacerbates wage inequality across plants.

The Kremer-Maskin model has three implications relevant for our analysis. First, increases in the cross-worker dispersion of skill results in increased segregation of workers by skill across plants. Second, if the overall distribution of skills is sufficiently dispersed, an increase in the mean level of worker skill will lead to an increase in the dispersion of wages 
across skill levels and plants. Third, if the overall distribution of skills is sufficiently dispersed, an increase in the mean level of skill leads to an increase in the cross-plant dispersion of productivity. The Kremer-Maskin model is silent about the sources of the changes in the distribution of skills. They argue that the change could come from an exogenous change in the distribution of skills in the workforce and/or from skill-biased technical change that changes the effective skill distribution.

To summarize, both the Caselli (1999) and the Kremer and Maskin (1996) models imply that there should be a positive correlation between changes in the dispersion of wages and productivity across plants. In contrast, if changes in institutional factors or shifts in product demand are the source of the increased wage dispersion, we would not unambiguously expect to see a positive correlation between changes in wage dispersion and changes in productivity dispersion across plants. Both Caselli and Kremer-Maskin offer additional predictions about the effects of a skill-biased technical change such as the computer revolution. The Kremer-Maskin model suggests that these changes will also be associated with an increase in the inter-plant segregation of workers by skill. The Caselli (1999) model predicts that changes in the distribution of wages and productivity across plants can be accounted for by changes in the distribution of capital in general and computers in particular across plants.

\section{Between-Plant and Within-Plant Components of Wage Dispersion}

In this section, we combine data from household and establishment surveys to decompose the variance of hourly manufacturing wages into between-plant and within-plant components. The decomposition methodology is from Davis and Haltiwanger $(1991,1996)$. The analysis in this section extends their results over a longer time period and incorporates nonproduction workers who work in auxiliary establishments such as central administrative offices, research 
facilities, and warehouses. The variance of hourly wages across hours worked in the manufacturing sector can be written as:

$$
V=\alpha V^{p}+(1-\alpha) V^{n}+\alpha(1-\alpha)\left(W^{p}-W^{n}\right)^{2}
$$

where $\alpha$ denotes production workers' share of hours worked, $\mathrm{V}^{\mathrm{p}}$ denotes the variance of wages across hours worked by production workers, $\mathrm{V}^{\mathrm{n}}$ denotes the variance of wages across hours worked by nonproduction workers, $\mathrm{W}^{\mathrm{p}}$ is the hours-weighted mean of the production worker wage, and $\mathrm{W}^{\mathrm{n}}$ is the hours-weighted mean of the nonproduction worker wage. Equation (1) expresses the total variance of hourly wages as the hours-weighted sum of the variances of production and nonproduction workers along with a term reflecting the contribution of differences in the mean wages across production and nonproduction workers. For each worker type, the variance can be further decomposed as:

$$
V^{j}=V_{B P}^{j}+V_{W P}^{j} \text { for } j=p, n
$$

where $\mathrm{V}_{\mathrm{BP}}^{\mathrm{j}}$ represents the between plant component and $\mathrm{V}_{\mathrm{WP}}^{\mathrm{j}}$ the within plant component for worker type $j$.

To estimate the components of the decompositions in (1) and (2) for the manufacturing sector we proceed as follows. We utilize household data from the 1975 through 1993 March Current Population Survey (CPS) and establishment data from the Longitudinal Research Database (LRD) ${ }^{8}$ From the individual-level wage observations in the CPS files, we calculate $\alpha$,

${ }^{8}$ Section A of the data appendix provides a detailed discussion of the problems that arise when combining information from household and establishment surveys. These measurement difficulties suggest that the results in Section III must be interpreted with appropriate caution. However, these measurement difficulties should primarily impact levels rather than time series 
$\mathrm{V}, \mathrm{V}^{\mathrm{p}}, \mathrm{V}^{\mathrm{n}}, \mathrm{W}^{\mathrm{p}}, \mathrm{W}^{\mathrm{n}}$ for all workers employed in manufacturing in each of the years under consideration (1975-1992). We also generate the production and nonproduction variances at the two-digit SIC industry level. From the plant-level observations in the LRD, we calculate the between-plant component for each worker type for each of the corresponding years at the twodigit level. For each worker type, we generate the within-plant component in equation (2) by taking the difference between the total variance calculated from the CPS and the between-plant variance calculated from the LRD at the two-digit level. ${ }^{9}$ Appropriately aggregating the between and within plant components across industries yields the decomposition at the total manufacturing level. As part of this aggregation, we decompose the overall between-plant component for each worker type into a between-plant, within-industry component and a betweenindustry component.

The results from the formal decomposition of total variance into between- and withinplant components based upon equations (1) and (2) are reported in Table 1 and Figure 1. Table 1 includes just selected years while Figure 1 depicts the patterns of the components for all years from 1975-92. While the formal decomposition is in terms of levels of hourly wages we are concerned about the possible effects of changes in scale. Therefore, the components in Figure 1 are depicted in terms of coefficients of variation.

There are several striking patterns in Table 1 and Figure 1. Focusing first on Figure 1 we see that the increased dispersion in overall hourly wages across workers in manufacturing over the 1975-92 period (measured by the coefficient of variation) is associated primarily with an

changes.

${ }^{9}$ Summary statistics for the CPS and LRD wage data are presented in Table A1 of the data appendix. 
increase in the dispersion of hourly wages between plants. Between-plant dispersion for both production and nonproduction workers increases over this time period (the dotted line). In contrast, the within-plant components do not exhibit a positive trend over this period (the dashed line). Within-plant dispersion for production workers exhibits no trend while within-plant dispersion for nonproduction workers exhibits a negative trend. In Table 1 we see that for total workers the story is still one of dominant and rising between-plant wage dispersion. However, the within-plant wage dispersion across all workers is also rising which differs from the patterns of within-plant dispersion of the two worker types. This divergence in the within-plant patterns is possible because total worker within-plant wage dispersion consists of an additional component, the within-plant wage gap between worker types. ${ }^{10}$ This within-plant wage gap can be thought of as the within-plant component of the cross-wage term $\left(\mathrm{W}^{\mathrm{p}}-\mathrm{W}^{\mathrm{n}}\right)$ shown in equation (1). Over the period of analysis, the within-plant wage gap has been rising. Moreover, the within-plant wage gap's share of total within-plant variance has grown from $25 \%$ in 1977 to $49 \%$ in 1992 . Thus, interestingly, within-plant dispersion by worker type has been steady or even declining but there has been some offsetting increase in the gap between production and nonproduction wages within plants.

The bulk of overall wage dispersion is accounted for by between-plant dispersion and the contribution of this has been growing over time. Combining the contribution of between-plant wage dispersion for production and nonproduction workers in the lower panel of Table 1 shows that $53 \%$ of the overall variance in 1977 is directly accounted for by between-plant differences in

${ }^{10}$ Specifically the decomposition of the within plant component is: $\mathrm{V}_{\mathrm{WP}}=\alpha \mathrm{V}_{\mathrm{WP}}^{\mathrm{p}}+(1-\alpha) \mathrm{V}_{\mathrm{WP}}^{\mathrm{n}}+\sum_{\mathrm{e}} \mathrm{s}_{\mathrm{e}} \alpha_{\mathrm{e}}\left(1-\alpha_{\mathrm{e}}\right)\left(\mathrm{W}_{\mathrm{e}}^{\mathrm{P}}-\mathrm{W}_{\mathrm{e}}^{\mathrm{N}}\right)^{2}$. Where the $e$ subscript denotes an establishment and $s_{e}$ is the establishment's share in total hours. 
wages. In 1992, the contribution of between-plant differences to overall dispersion is $64 \%$.

Table 1 provides a further decomposition of the between-plant components into between-plants, within-industries and between industries. For this purpose, industries are defined at the two-digit level. The results indicate that most of the between-plant contribution arises from differences in wages between plants within the same industry. ${ }^{11}$ The result that much of the increase is due to an increase in the between-plant dispersion within industries indicates that explanations that rely on shifts between industries (e.g., simple product demand shifts across industries) cannot account for the rising dispersion.

There is greater dispersion among nonproduction workers than among production workers. This fact combined with an increased nonproduction worker labor share over this time period has yielded an increasing share of overall dispersion being accounted for by differences in wages among nonproduction workers. Another contributing factor to overall increases in dispersion is a widening gap between production and nonproduction worker wages. The gap between production and nonproduction worker wages accounts for $8 \%$ of overall dispersion in 1977 and $11 \%$ of overall dispersion in 1992.

To help quantify the extent of the changes in the components of the wage variation shown in Figure 1, Table 2 shows the Kremer-Maskin segregation index for all workers, production workers, and nonproduction workers by Census years. This index measures how correlated the

11 The finding that most of the increase in between plant increase in wage dispersion is a within industry phenomenon is reinforced in results reported in Section $V$ that consider four-digit industry effects. The results in this section only consider two-digit industry since this is the level of aggregation at which the LRD and CPS statistics can be readily matched. However, for the purposes of investigating the role of between vs. within industry contributions of the between plant changes in dispersion, there is no need to restrict analysis to the two-digit level. In Section $\mathrm{V}$, we report results that show that the fraction of overall dispersion accounted for by four-digit industry effects falls between 1977 and 1992. 
skill levels of workers are within a plant. Specifically, it is the ratio of the variance of the mean skill level between plants to the variance of the skill level of the total population. It is equivalent to the $R^{2}$ of a regression of skill level on a series of plant dummies. When $R^{2}=0$ there is no segregation, when $\mathrm{R}^{2}=1$ there is complete segregation. In this case, skill level is measured by wages. From Table 1 and Figure 1, it is evident that the between component has been increasing over time while the within component has been relatively flat, and hence the segregation index will be generally rising over time. ${ }^{12}$ The change in segregation for nonproduction workers is especially stark.

To sum up, we find that the between-plant components of dispersion are an important fraction of overall wage dispersion and account for all of the increase in overall dispersion in the 1975-92 period. These results parallel and extend similar findings in Davis and Haltiwanger $(1991,1996)$ and in Kremer and Maskin (1996). Moreover, we believe the evidence in this section makes a strong case that accounting for the sources of the increase in overall wage dispersion necessitates accounting for the sources of the increase in between-plant wage dispersion. Accordingly, this gives us confidence to proceed with the remainder of the analysis which investigates the sources of between-plant changes in wage dispersion along with potentially related between-plant changes in productivity dispersion. Before proceeding with that analysis, however, we first document the plant-level link between wages and productivity.

\section{Linking Productivity and Wages}

In this section, we provide a basic description of the relationship between wages and productivity at the sector, industry, and plant level. Figure 2 provides some prima facie evidence

\footnotetext{
${ }^{12}$ Within this general trend of an increase over the years, there is apparently some cyclical variation in the degree of segregation by skill.
} 
that changes in wage and productivity dispersion are closely linked. The upper panel of Figure 2 presents measures of wage dispersion. Using data from the March Current Population Survey (CPS), the solid line in the upper panel depicts the hours-weighted 90-10 differential of hourly $\log$ wages for $1975-92 .{ }^{13}$ As is now well-known, there has been a sustained increase in the dispersion of wages among workers over this period of time. Somewhat less well-known is that the increase in dispersion among all workers is mimicked by an increase in dispersion among workers employed in manufacturing industries. Again, using the CPS, the dashed line in the upper panel shows that the pattern for workers in manufacturing closely tracks that for all workers. The similar time series pattern suggests that similar factors underlie the changes for all workers and the changes for manufacturing workers. Put differently, although our plant-level analysis is confined to manufacturing, it likely has wider applicability.

The lower-panel of Figure 2 depicts the hours-weighted 90-10 between-plant differential of $\log$ output per hour across U.S. manufacturing plants. Interestingly, it also exhibits a sustained increase over this period of time. Comparing the upper and lower panels suggests that it may be possible to identify common factors underlying the secular increases in wage and productivity dispersion. However, there are some notable differences in the timing of the secular changes. While wage dispersion increases steadily after 1979, productivity dispersion only increases steadily after the early 1980 s recession.

${ }^{13}$ The 90-10 differential is measured as the difference between the hourly log wage for the worker at the 90th percentile of the hourly log wage distribution for a given year and the hourly $\log$ wage of the worker at the 10th percentile of this distribution. In this and subsequent analysis using 90-10 differentials, the respective distributions are the total hours weighted distributions across plants or workers. Details of measurement of wages and productivity from the CPS and LRD are discussed in Section A of the data appendix. 
Certainly, the aggregate data series suggest that there may be a close link between changes in wage dispersion and changes in productivity dispersion in the manufacturing sector. However, we also need to establish that there is a link between productivity and wages at the plant and industry level. We begin first by documenting the relationship between productivity and wages at the plant level. The simple cross-sectional correlation between plant wages and plant labor productivity averages .55 indicating that plants that have higher wages also tend to have higher levels of labor productivity. This correlation is almost constant over time varying between .52 and .57 for all years between 1975 and 1992 and is statistically significant at the .0001 level in all years. Next, we examine the relationship between plant-level changes in wages and plant-level changes in productivity. We construct the correlation between plant-level changes in productivity and plant-level changes in log average hourly wages for 12,904 plants that appear in our data in the four Census years: 1977, 1982, 1987 and $1992 .{ }^{14}$ The correlations are .35 for the 1977-1982 period, .36 for the 1982-1987 period, and .39 for the 1987-1992 period and all statistically significant at the .005 level.

Further evidence that changes in wage and productivity dispersion are linked is provided by examining cross industry differences in the changes in the between-plant dispersion of these distributions. Panel A of Figure 3 presents the scatter plot of 1977-92 changes in the 90-10 between-plant differential in log hourly wage and the 90-10 between-plant differential in log labor productivity for each four-digit industry. Panels B-D present analogous scatter plots relating the changes in the dispersion of nonproduction worker wages, production worker wages, and the nonproduction labor share, respectively, to changes in the dispersion of labor

${ }^{14}$ Census years are the only years for which we can measure changes for all of the surviving plants in our data. 
productivity (all measured using the 90-10 differential). Also, reported in each figures is the correlation of the depicted changes as well as the regression line that results from a simple bivariate regression of the changes depicted in the scatter plot.

Panel A shows that there are considerable cross industry differences in the changes in between-plant wage and productivity dispersion. Some industries exhibit dramatic increases in wage dispersion while others exhibit dramatic decreases. The same holds true for productivity dispersion. Moreover, there is a strong positive relationship between the changes in wage and productivity dispersion by industry. The pattern in Panel A is mimicked by similarly strong positive relationships of between-plant productivity dispersion with changes in between-plant measures of production worker wage (Panel B) and nonproduction labor share (Panel D) by industry. There is a positive but weaker relationship between the changes in between-plant productivity dispersion and nonproduction wage (Panel C) by industry.

We interpret the simple correlations as demonstrating that there exists a positive crossplant relationship in the level of wages and productivity and a positive cross-plant relationship in the changes in wages and productivity. We interpret the evidence in Figure 3 along with the aggregate time series evidence in Figure 2 as compelling evidence that both cross-plant changes in wage and productivity dispersion are closely linked.

To sum up the findings thus far, we have found that much of the increase in overall wage dispersion is due to an increase in the between-plant dispersion within industries. This evidence in itself is interesting as it indicates that the rising wage dispersion is associated with greater segregation by worker skill (as measured by wages). In addition, the findings in this section make clear that the rising wage dispersion within industries is accompanied by rising productivity dispersion within industries. These findings alone are consistent with the 
hypothesis that there are some underlying changes in the technology and/or worker mix across plants driving the changes in wage dispersion. Explanations that rely on shifts between industries (e.g., simple product demand shifts across industries) cannot account for these patterns. While this evidence is suggestive, we have not yet identified observable changes in technology across plants that can account for the dominant role of these between-plant changes. In the subsequent sections, we investigate the role of observable factors such as changes in capital intensity and the role of computers across plants as potential indicators of the changes in technology across plants.

\section{Analysis of the Sources of Changes in Dispersion of Wages and Productivity}

The objective in this section is to investigate the role of observable changes in technology in accounting for the observed changes in wage and productivity dispersion. Our emphasis in this analysis is on the change in capital intensity and computer usage across plants. This emphasis is very much driven by the insights of the Caselli (1999) paper discussed in section II that predicts a close correspondence between changes in capital intensity and the use of advanced technology and changes in wage and productivity distributions across plants. After specifying our methodology, we first attempt to understand the role of observable factors on the overall changes in the wage and productivity distributions. Following this analysis, we exploit the substantial differences in the within industry changes of wage and productivity dispersion across industries to consider another angle on the role of observable changes in technology.

\section{A. Specification for Full Distribution Accounting Decomposition Exercises}

In this section of the paper, we examine in greater detail the sources of the change in between-plant dispersion for wages, productivity, and workforce structure. Our approach will follow Juhn, Murphy, and Pierce (1993) (hereafter JMP), and, in particular, Davis and 
Haltiwanger $(1991,1996)$ who utilize the JMP full distribution accounting methodology in a similar setting. Davis and Haltiwanger examine changes in between plant wage dispersion focusing on the role of size in accounting for these changes. In this paper we also control for size but focus on the relative importance of computer investment and capital intensity in accounting for changes in the dispersion of wages and productivity. While the influence of computer use and computer investment has been the examined in the context of explaining changes in the mean of the distribution of wages (e.g., Krueger (1993), and Autor, Katz, and Krueger (1998)), and average productivity (Berndt and Morrison (1992), Oliner and Sichel (1994), and Siegel (1997)), little analysis has been undertaken investigating the role of computers in accounting for changes in dispersion of these variables.

The analysis starts with specification of a basic regression model of the following form:

$$
y_{i t}=X_{i t} \beta_{t}+\mu_{i t}
$$

where our plant-level variable of interest, $y_{i t}$, is wages, productivity, or workforce structure for plant $i$ in period $t, X_{\mathrm{it}}$ is a matrix of observable plant characteristics, $\beta_{\mathrm{t}}$ is a parameter vector, and $\mu_{\mathrm{it}}$ is the residual of the regression. ${ }^{15}$ The residual term $\left(\mu_{\mathrm{it}}\right)$ takes the form $\mu_{\mathrm{it}}=\mathrm{F}_{\mathrm{t}}^{-1}\left(\omega_{\mathrm{it}} \mid \mathrm{X}_{\mathrm{it}}\right)$

15 The estimated parameters do not have a direct structural interpretation - rather they are measures of the covariance structure in the data between measures of outcomes and plant characteristics. The theories we outline have predictions about the changes in this covariance structure which we attempt to test. Thus, for example, the estimated coefficient on capital intensity in the labor productivity equation should not be interpreted as a structural estimate of output elasticity from a specification of an intensive production function. The reason for this is that the coefficient may reflect unobserved technology effects that are correlated with capital intensity. In our setting, it is explicitly hypothesized that such unobserved technology effects may be correlated with observables like capital and computer intensity. Moreover, the theories we are investigating suggest the nature of these unobserved technology effects may have changed over time (e.g., skill biased technical change that is embodied in observable indicators of technology like capital intensity and computer intensity) so that the covariance between measures 
where $\omega_{\mathrm{it}}$ gives the plant's position in the distribution of residuals in year $t$ and $\mathrm{F}_{\mathrm{t}}^{-1}\left(\cdot \mid \mathrm{X}_{\mathrm{it}}\right)$ represents the inverse cumulative distribution function of the residuals in year $t$, which may vary with the observable plant characteristics. Given this form one can imagine independently varying the position (or percentile) occupied by each plant $\left(\omega_{\mathrm{it}}\right)$ and the distribution function $\left(\mathrm{F}_{\mathrm{t}}^{-1}\left(\cdot \mid \mathrm{X}_{\mathrm{it}}\right)\right)$. We can then decompose the change in the dispersion of the dependent variable $\left(\mathrm{y}_{\mathrm{it}}\right)$ into three components based on the regression model -- changes in the distribution of observable plant characteristics (changes in the X's), changes in the differentials associated with the effect of the observables on the dependent variable (changes in the $\beta$ 's), and changes in the distribution of the unobservables (changes in the $\mu$ 's). This decomposition is what we call the JMP decomposition and is given as:

$$
y_{i t}=X_{i t} \bar{\beta}+\overline{F^{-1}}\left(\omega_{i t} \mid X_{i t}\right)+X_{i t}\left(\beta_{t}-\bar{\beta}\right)+\left(F_{t}^{-1}\left(\omega_{i} \mid X_{i t}\right)-\overline{F^{-1}}\left(\omega_{i t} \mid X_{i t}\right)\right)
$$

where $\bar{\beta}$ is the average effect of the observables on the dependent variable over the whole period and $\bar{F}^{-1}\left(\cdot \mid X_{i t}\right)$ is the average inverse cumulative distribution function. The first two terms in equation (4) capture the impact of changes in the distribution of observable characteristics for given effects of these observables. The third term captures changes in the differentials associated with the observable characteristics. The final term (in parentheses) captures the contributions of changes in the distribution of regression residuals that are unexplained by changes in the $\beta$ 's and changes in the distributions of the X's.

of outcomes like productivity and these measures may have changed over time. 
To intuitively understand this decomposition, consider decomposing the change in the distribution of labor productivity between 1977 and 1992 into its three components. ${ }^{16}$ First one computes the actual distribution of plant-level labor productivity for 1977 and then from this distribution computes a sample statistic such as the difference in labor productivity of plants at the $90^{\text {th }}$ and $10^{\text {th }}$ percentiles of the distribution. One next computes the same distribution but allowing the X's to change to their 1992 value and then computes the 90-10 differential in labor productivity from this hypothetical distribution. The difference in the 90-10 differential from the actual distribution and the 90-10 differential from this hypothetical distribution is the change in the overall labor productivity distribution attributable to the change in the distribution of observable characteristics (the X's). Next one computes the distribution of productivity allowing both the X's and the $\beta$ 's to change to their 1992 value and computes the $90-10$ differential from this new hypothetical distribution. The difference between the 90-10 differential from this new distribution and the $90-10$ differential from the actual distribution is the change in the overall distribution attributable to the change in the distributions of both the X's and the $\beta$ 's. To obtain the marginal contribution of just the $\beta$ 's one compares this change with the change in the overall distribution attributable to the change in the distribution of the X's. The marginal contribution of changes in the distribution of the residuals is then just the total change in the 90-10 differential of the actual distribution minus the change due to changes in both the X's and the $\beta$ 's.

To actually perform this decomposition using equation (4) the change in the overall distribution attributable to changes in the distribution of the X's is found by comparing the change in the 90-10 differential generated by the first two terms of equation (4) with the actual

\footnotetext{
${ }^{16}$ A more detailed explanation of the JMP methodology can be found in Juhn, Murphy and Pierce (1993), Davis and Haltiwanger $(1991,1996)$ and Goldin and Margo (1992).
} 
change in the 90-10 differential of the dependent variable. Computing the marginal contribution of the $\beta$ 's involves comparing the change in the distribution of the dependent variable implied by the first three terms of the equation with the change in the distribution implied by the first two terms. The marginal contribution of changes in the distribution of the residuals that are not accounted for by changes in the $\beta$ 's and the X's is found in an analogous fashion. ${ }^{17}$ In what follows, we focus our attention on decomposing changes in dispersion as measured by changes in the $90-10$ percentile range. ${ }^{18}$

\section{B. Basic Characteristics of the Plant-Level Data.}

The data used to examine between-plant changes in the dispersion of productivity, wages, and workforce composition come from the same source as the plant-level wage data employed in the prior section. This analysis focuses on explaining the changes in dispersion in five plantlevel variables: the log of output-per-hour, the log of average plant hourly wages, the log of average plant production worker hourly wages, the log of average plant nonproduction worker hourly wages, and the nonproduction labor share of employment. Our productivity variable, the

${ }^{17}$ We should note that it is possible to get different results depending on the order of the decomposition as well as which year serves as the base year. We deliberately chose to put observable quantities first to give them the greatest opportunity to account for the changes in dispersion.

${ }^{18}$ The careful reader will note that a number of alternative characterizations of dispersion are considered in the paper. In Section II, the variance decomposition is conducted in natural units (as required formally) and components of the decomposition in Figure 1 are depicted in terms of coefficients of variation. In Figure 2, as well as in this section, we focus on the 90-10 differentials of $\log$ wages per hour at the plant-level and log productivity at the plant-level. Comparing across dispersion measures (e.g., standard deviation of log wages, coefficient of variation in natural units, 90-10 differential in log wages), we find similar qualitative and quantitative patterns in the behavior of between-plant wage and productivity dispersion. For the analysis in this section, we focus on the 90-10 differential in log wages and productivity since we believe this approach provides the most robust characterization of the relationship between changes in plant-level observables and changes in wage and productivity dispersion. 
$\log$ of output-per-hour, is defined as the total value of shipments from the plant, measured in constant 1987 dollars, divided by total plant hours. ${ }^{19}$ The output data are deflated by the fourdigit industry price deflators found in the Bartelsman and Gray (1996) productivity data set. The wage variables are measured in the same fashion as in the preceding section. The last variable, the nonproduction labor share, is our attempt to capture changes in the composition of the workforce in manufacturing establishments. Papers such as Autor, Katz and Krueger (1998), Berman, Bound and Griliches (1994), Caselli (1999), Dunne, Haltiwanger, and Troske (1997), and Kremer and Maskin (1996) have interpreted this variable as representing a measure of workforce skill. ${ }^{20}$

The observable plant characteristics contained in the X matrix include four-digit SIC industry controls, nine census region dummies, a set of nine size class variables, a multi-unit dummy variable, a measure of capital intensity, and computer investment per worker. While the specification is relatively parsimonious, it allows us to examine two variables of interest -computer investment per worker and capital intensity. In what follows, we permit the

${ }^{19} \mathrm{As}$ in the previous section, we estimate the number of hours for nonproduction workers based on the CPS average annual hours worked per nonproduction worker for each two-digit industry and apply these two-digit aggregate average hours worked for a nonproduction worker to the plant-level nonproduction worker variable.

${ }^{20}$ Both Dunne, Haltiwanger and Troske (1997) and Berman, Bound and Griliches (1994) discuss at considerable length the pro's and con's of using nonproduction labor share as a measure of skill. It is well documented that nonproduction workers are generally more educated than production workers as a group. However, it is also the case that the nonproduction worker group includes both workers that would be considered more skilled than the typical production workers (engineers, managers, programmers) but also includes a set of workers that may be less skilled (janitors, guards). Thus, one should be somewhat cautious in interpreting the nonproduction labor share as an index of workforce skill. 
coefficients on each of the plant measures (i.e., size dummies, multi-unit dummy, capital intensity and computer investment per worker) to vary by two-digit industry.

The computer investment variable at the plant-level is computer investment per worker. While we would prefer to have a measure of the stock of the computing equipment at each point in time, this information is unavailable. Therefore, we use computer investment per worker in the plant as a proxy for computers per worker in the plant (see Berman, Bound and Griliches (1994) for a justification). The use of the computer investment variable restricts our analysis to census years (the only years the computer investment question is asked) and reduces the sample size because of the low response rate to this question. ${ }^{21}$ One problem with using the computer investment information is that because of dramatic changes in computer quality it is difficult to turn nominal dollars of computer investment into real dollars of investment. To circumvent this problem in the regressions, we construct a relative measure for each plant-year observation computed as the ratio of computer investment per worker at the plant-level to the mean of this variable across all plants in the year. ${ }^{22}$ By using this relative measure, we are only exploiting the within year, between-plant variation in computer investment per worker in our analysis.

We measure capital intensity at the plant level as the real value of capital divided by total worker hours. Following Baily, Hulten and Campbell (1992) we construct the real value of capital by multiplying the book value of capital at the plant by the ratio of the real value of capital to the book value of capital in the two-digit industry. Because we are again concerned

${ }^{21}$ See Troske (1996) for a discussion of the computer investment question on the Annual Survey of Manufactures (ASM). On average $60 \%$ of plants in the ASM respond to this question in each year.

${ }^{22}$ As will become clear below, we could not use a log measure in this case since there are many plants that report zero computer investment. 
about our ability to turn nominal capital stock numbers into real dollars, we also use a relative measure of capital intensity by computing for each plant-year the difference between the log capital intensity and the overall average of this log measure for the year. This again ensures that we are only exploiting the within year, between-plant variation in capital intensity in our analysis. $^{23}$

Table 3 presents some basic descriptive statistics for each of the variables for the years 1977, 1982, 1987, and 1992. The statistics are hours weighted means and standard deviations. Panel A represents all plants used in the analysis in Section III. Panel B represents a restricted sample that includes all plants that report detailed investment data. The restricted sample forms the basis of the regression and decomposition analyses in this section. The basic statistics show that for the wage, productivity, and nonproduction labor share variables between plant dispersion has increased over the 15 year period for both samples. These patterns for productivity and wages were noted earlier in the paper. The same is true for the nonproduction labor share variable though the increase in the standard deviation is relatively small. ${ }^{24}$

The bottom two rows of Panel B report the summary statistics for the capital-labor ratio and the computer investment per worker variables. The mean of the capital-labor ratio has risen markedly over the period while the dispersion in the capital-labor ratio has remained nearly

\footnotetext{
${ }^{23}$ Measuring computer investment and capital intensity in this manner will only affect the coefficients on these variables in the pooled regression, it will have no effect in the cross sectional regressions that go into the JMP analysis. We have repeated the JMP analysis using an the absolute measure of computer investment and capital intensity and the results are similar.

${ }^{24}$ Panel A of Figure A.5 below presents the time-series pattern of the $90-10$ differential in the nonproduction labor share over the period 1977 through 1992. The graph shows that the dispersion in the nonproduction labor share variable increases over the time period and the increase is concentrated between 1977 to 1982 .
} 
constant over the period. It is important to note that the standard deviation of the capital-labor ratio is quite large implying that even a small change in the wage or productivity differential associated with capital intensity can have a very large impact on the distribution of wages or productivity. With respect to the computer investment per worker variable, both the mean and standard deviation have increased over time. The sharp rise in the mean of computer spending per worker represents two forces at work. First, the percentage of plants that report positive investment expenditures on computing equipment rises sharply over the period. In $1977,10.2 \%$ of plants report positive computing expenditures while $61.9 \%$ report positive computing expenditures in 1992. Second, the mean real computer spending per employee for plants with positive spending on computer investment increased from $\$ 96$ to $\$ 1080$ over the period..$^{25}$ C. Summary Statistics on Basic Regression Results

Before proceeding to the JMP full distribution accounting exercises, we present summary information on the basic regression results. Table 4 presents selected summary parameter estimates from the regressions involving each of the five dependent variables under consideration: labor productivity, hourly wages, production worker wages, nonproduction worker wages, and nonproduction labor share. To implement the JMP exercises, the specifications are estimated for each year and are also estimated pooling the data across years (to obtain the fixed $\beta$ component). Recall that the regression models allow for the coefficients on the computer investment and capital intensity variables to vary across two-digit industry. Thus, for each

${ }^{25}$ In nominal terms, the change in computer investment per worker in plants with positive computer investment is considerably more muted going from \$452 in 1977 to $\$ 602$ in 1992. However, if plants investing zero in computer investment are included in the construction of the mean, then computer investment per worker is eight times larger in 1992 as compared to 1977. 
dependent variable, we have 19 computer investment coefficients and 19 capital intensity coefficients in each year (as well as the coefficients from the pooled specification). ${ }^{26}$

Table 4 reports the mean and the range of the coefficients for the computer and capital variables for the base specification. For each of the dependent variables under consideration, the computer investment per worker coefficients change substantially over time. For example, in 1977 , the average computer investment per worker coefficient in the productivity regressions is -.0016 . However, by 1992 , the average coefficient increases substantially to $.0211 .^{27}$ This upward trend in the computer investment coefficients is exhibited for all five dependent variables. In 1992, plants with higher levels of computer investment per worker had higher levels of productivity, wages, and nonproduction labor share. In addition, to the computer variable we also present summary information for the capital intensity coefficients. The average capital intensity coefficient has also tended to increase over time, although the patterns are not as systematic or monotonic across dependent variables. For example, the average capital intensity coefficient in the productivity regression increases from 0.2285 in 1977 to 0.2635 in 1987 but then falls to 0.2361 in 1992. Of course, considerable caution must be used in translating these changes in average industry coefficients into the implied changes in wage and productivity dispersion since ultimately we need to consider the interaction between the changes in the coefficients for every industry with the changes in the dispersion in capital and computer

\footnotetext{
${ }^{26}$ Because of small sample sizes, we have combined plants in the Food industry (20) and the Tobacco industry (21) into one industry, giving us 19 two-digit industries.

${ }^{27}$ Note that this changing correlation between computers and productivity may be part of the reason that there has been considerably disagreement over the relationship between computer use and productivity in the recent literature. Studies such as Morrison and Berndt (1991) and Oliner and Sichel (1994) found little correlation between productivity and investment in computers while Lichtenberg (1993) and Siegel (1997) report a positive correlation.
} 
intensities in each industry. Indeed, it is via the JMP exercises that we consider this interaction since the JMP methodology itself provides the appropriate weighting and aggregation of the changes in characteristics and the changes in differentials associated with these characteristics.

To provide some perspective on the fit of the base model, and the influence of individual variables on the explained variation of the model, Table 5 presents adjusted R-squared statistics for a number of alternative specifications of the model. We consider three alternative model specifications: the model with all controls, the model with computers only (allowing the coefficients to vary across two-digit industry), and the model with capital only (allowing the coefficients to vary across two-digit industry). The full model (all controls) accounts for a substantial amount of the cross-sectional variation in the productivity, hourly wage, production worker wages and nonproduction labor share regressions. Somewhat surprisingly, the fraction of the variance of productivity and wages accounted for by the variables in the full model falls over this period. In contrast, the model that only includes the computer variable accounts for little of the overall variation in any of the dependent variables, though computers account for a significantly greater fraction in 1992 as compared to 1977 across all five dependent variables. The model that includes only the capital variable accounts for a significant fraction of the overall cross-sectional variation and this fraction tends to increase over time although not dramatically or monotonically. Interestingly, the decrease in the R-squared in the full model is driven by a decrease in the fraction of the variance accounted for by four-digit industry effects. ${ }^{28}$ As noted in Section III, the rising between plant dispersion in wages is a within-industry phenomenon.

${ }^{28}$ For example, for productivity, the R-squared from a specification with four-digit industry effects only falls from 0.62 to 0.53 over the period 1977 to 1992 . The analogous change for hourly wages is 0.51 to 0.49 . 
These results reinforce this finding. Moreover, as we will see below, it is noteworthy that some variables (e.g., computers) account for a larger fraction of the variance over time while others (e.g., industry) account for a smaller fraction of the variance over time.

\section{Full Distribution Accounting Exercises}

Utilizing the information from the regressions, we examine changes in the dispersion of the between-plant wages, labor productivity, and workforce structure using the JMP analysis discussed above. In the results reported in the paper, we do not condition the residual distribution on any observable variables. ${ }^{29}$ We consider the implications of our analysis for both the overall time series changes in dispersion and for the cross-industry patterns of changes in wage and productivity dispersion.

Table 6 reports summary measures of the decompositions in terms of the long run changes in dispersion from 1977-92. ${ }^{30}$ To start with focus on changes in the distribution of labor productivity (column 1). In the full model, changes in the distribution of observables for fixed $\beta$ 's yield a decrease in labor productivity dispersion from 1977-92, while changes in the $\beta$ 's account for almost $70 \%$ of the $1977-92$ change (Panel A). The remaining fraction is accounted for by changes in the distribution of the unobservables.

29 In unreported results, we have conditioned the residual distribution on industry controls. For the aggregate time series decompositions, we obtain qualitatively similar results to those reported here. However, conditioning the residual distribution on industry controls is inappropriate for our industry-level decompositions and thus for comparability we restrict our attention in the characterization of aggregate decompositions to those that do not condition the residual distribution on industry controls.

${ }^{30}$ While our discussion in this section of the paper focuses on changes in dispersion over the entire 15 year period (1977 to 1992), Section B of the appendix presents the JMP analysis of changes in dispersion for the three subperiods 1977-1982, 1982-1987, and 1987-1992 as well. 
The results for labor productivity based upon computer investment per worker only (Panel B) or capital intensity only (Panel C) yield a somewhat larger contribution of the observable characteristics compared to the full model and, like the full model, a large contribution of changes in the $\beta$ 's. In both cases, the fraction of the 1977-92 change in productivity dispersion accounted for by changes in the $\beta$ 's is quite large. These results indicate that a large fraction of the increase in labor productivity dispersion is associated with increases in the productivity differential across high and low computer investment per worker plants and across high and low capital intensity plants.

For the computers and capital only specifications, the contribution of the unobservables is quite small and much smaller than for the full model. How can the unobservables in the more restricted models account for a smaller fraction of the time series changes? It is important to remember that the exercise here is to decompose changes in dispersion, not levels of dispersion. Table 5 makes clear that the full model accounts for a much larger fraction of the level of dispersion in any given year. For changes in dispersion, it is useful to emphasize that changes in the distribution of some variables may act to increase dispersion, while changes in the distribution of other variables may act to decrease dispersion. Similarly, changes in the differentials associated with some observables may increase dispersion, while others may decrease dispersion. In the case of productivity dispersion, there are clearly changes in the contribution of observable factors other than capital intensity and computer investment per worker that are acting to decrease the dispersion in between plant productivity.

The next three columns in Table 6 (2,3, and 4), deal with changes in the dispersion of our three wage variables - the log of average hourly wage, the log of the average production worker hourly wage, and the log of the average nonproduction worker hourly wage. For the full model, 
the hourly wage results show that changes in the distribution of the observables for fixed $\beta$ 's play little role in increasing wage dispersion, while the contribution due to changes in the differentials associated with the characteristics (the $\beta$ 's) is substantial. For the full model and the model with computers only, the contribution of changes in the $\beta$ 's to the $1977-92$ change is around $50 \%$ while for the capital only model the contribution is greater than $80 \%$. Like the results for productivity dispersion, these results indicate that a large fraction of the increase in wage dispersion is associated with increases in the wage differentials across high and low computer investment per worker plants and especially across high and low capital intensity plants.

The results for production workers' wages are quite similar to the results for average hourly wage. For the full model, we find that the changes in the distribution of observable characteristics for fixed $\beta$ 's actually decrease overall dispersion. In contrast, changes in the differentials associated with the characteristics account for a substantial fraction of the increase in dispersion. For the computers and capital only models, it is again changes in the $\beta$ 's that are the most important. In the case of the nonproduction workers, similar results are observed, although unobservables account for a larger fraction of the overall change in dispersion.

Turning to the nonproduction labor share results (Column 5) we find that changes in the distribution of characteristics for fixed $\beta$ 's play a more important role. Moreover, in this case, the full model yields a smaller contribution of unobservables to the overall time series change relative to the computer and capital only models. Still, we find that a large fraction of the increase in the dispersion in the nonproduction labor share is associated with increases in the difference in the nonproduction share between high and low computer investment per worker plants and high and low capital intensity plants. 
The net result of the JMP analysis is that changes in the wage and productivity differentials across high and low computer investment per worker plants and high and low capital intensity per worker plants account for a large fraction of the changes in wage and productivity dispersion from 1977 to 1992 . These results indicate that understanding the changes in wage and productivity dispersion lies in understanding increases in the wage and productivity differentials between high and low capital intensity plants and high and low computer investment per worker plants.

\section{E. Analysis of the 4-digit Industry Changes in Productivity and Wage Dispersion}

The previous section focused on examining changes in aggregate dispersion, we now turn our attention to considering the decompositions by detailed industry. Figures 4-6 provide results on the decomposition of changes by four-digit industry. Figure 4 presents results for all controls, Figure 5 for computers only and Figure 6 for capital only. Panel A of Figure 4 presents the scatter plot of predicted and actual four-digit industry changes in between plant labor productivity dispersion. The changes in dispersion reflect changes in the 90-10 differential from 1977 and 1992 for each four-digit industry. By predicted changes, we mean the changes accounted for by both changes in the distribution of observable characteristics (the X's) and changes in the differentials associated with these observables (the $\beta$ 's). Thus, for these four-digit industry exercises, we combine the contribution of changes in the characteristics and changes in the differentials associated with these characteristics from the JMP exercises. ${ }^{31}$ Panel B provides the analogous scatter plot for changes in actual and predicted between-plant wage

31 Note that in unreported results we have examined the separate contributions of the observable characteristics and the differentials associated with these characteristics for the fourdigit exercises. Like the aggregate exercises reported in Table 6 , we find that the more important contributing factor is changes in the differentials associated with the observable characteristics. 
dispersion at the four-digit industry level. Panel $\mathrm{C}$ shows the relationship between the predicted changes for productivity and wage dispersion from observables. Panel D shows the relationship between the changes accounted for by the unobservables for productivity and wage dispersion. Also, reported in each scatter plot is the simple correlation as well as the bivariate regression line implied by the changes depicted in the scatter plot.

Panel A indicates that observable characteristics and $\beta$ 's yield changes in between plant productivity dispersion at the four-digit level that are strongly correlated with the actual fourdigit industry level changes. We have also calculated the fraction of the change in dispersion accounted for by observables for each industry and the weighted average of this fraction is 0.22 (using the absolute value of the actual change for the industry as the weight). Panel B shows similar patterns for the relationship between actual and predicted wage changes. For wage changes, the weighted average fraction accounted for by observables is equal to 0.16 . Panel $\mathrm{C}$ indicates that the components of the four-digit industry changes in wage and productivity dispersion accounted for by observables are highly correlated. Panel D indicates that the components of the four-digit industry changes in wage and productivity dispersion accounted for by unobservables are also positively correlated but the correlation is substantially smaller.

Comparing Panels C and D to Panel A of Figure 4, the pattern that emerges is that the correlation between wage and productivity dispersion changes due to the components accounted for by the observables exceeds the correlation in actual changes which in turn exceeds the correlation due to the components accounted for by unobservables.

Figures 5 and 6 present the analogous exercises for the computers only and capital only specifications. For the computers only model (Figure 5), the predicted four-digit industry changes are virtually uncorrelated with the actual four-digit industry changes in dispersion for 
both wage and productivity dispersion. Apparently, computer investment per worker differences across plants are not particularly helpful in accounting for cross industry variation in the changes in productivity or wage dispersion. In spite of this finding, Panel C of Figure 5 shows that the components of industry level changes in wage and productivity dispersion accounted for by computer investment per worker effects are highly correlated.

The most interesting results for these four-digit industry exercises are found for the capital only specification (Figure 6). Like the full model, predicted changes at the four-digit level are strongly correlated with actual changes in wage and productivity dispersion. Moreover, the weighted average fraction of the four-digit industry level change accounted for by capital intensity differences across plants is 0.20 for productivity dispersion changes and 0.20 for wage dispersion changes. Panel $\mathrm{C}$ shows a very high correlation between the predicted changes in wage dispersion and productivity dispersion from capital intensity differences across plants. Apparently, capital intensity differences across plants yield a very strong relationship in changes in both wage and productivity dispersion by industry.

We summarize the four-digit industry exercises as follows. An important basic fact presented in Figure 3 is that industries with large changes in wage dispersion also tend to have large changes in productivity dispersion. The findings in this section indicate that the component of changes in wage dispersion accounted for by observables for a given industry is highly correlated with the component of changes in productivity dispersion accounted for by observables in that industry. This latter finding is especially strong for the results that focus on the contribution of differences in capital intensities across plants.

\section{Summary and Interpretation of Findings}


This paper has documented and analyzed changes in the dispersion in wages and productivity for the manufacturing sector. Our main findings are that (1) the between-plant component of wage dispersion is an important and growing part of total wage dispersion, (2) much of the between-plant increase in dispersion is within industries, (3) the between-plant measures of wage and productivity dispersion have increased substantially over the last few decades, (4) industries with large changes in between-plant wage dispersion also exhibit large changes in between-plant productivity dispersion, (5) a substantial fraction of the rising dispersion in wages and productivity is accounted for by increasing wage and productivity differentials across high and low computer investment per worker plants and high and low capital intensity plants, and (6) changes in dispersion accounted for by such observable characteristics yield predicted industry level changes in wage and productivity dispersion that are highly correlated.

The results are consistent with the predictions of the models of Kremer and Maskin (1996) regarding skill segregation across plants and the related model of Caselli (1999) regarding the role of differential technology adoption across plants in an environment with skill segregation and skill-biased technical change. These models predict rising between-plant wage and productivity dispersion which is consistent with our findings. Moreover, the Kremer and Maskin model predicts an increase in segregation by worker skill across plants which is also consistent with our findings. In addition, the Caselli model predicts that the rising wage and productivity dispersion across plants will be associated with differences in technology adoption across plants in response to a skill biased technological revolution. Our findings are consistent with this latter prediction in the sense that we find that a substantial fraction of the rising wage and productivity 
dispersion is accounted for by rising wage and productivity differentials across plants with different capital and computer intensities.

There are some important caveats to this interpretation of the results. First, unobservable factors still account for a large fraction of the increases in wage and productivity dispersion. Second, changes in observable quantities account for only a small fraction of the changes in wage and productivity dispersion. That is, it was not the case that we can account for much of the increase in wage and productivity dispersion by simply examining the differences in the magnitude of computer investment and/or differences in the changes in capital intensity across plants, for given differentials associated with those factors. Instead, it is the changes in the differentials associated with these factors that are important in this context. This aspect of the findings is seemingly inconsistent with the predictions of the Caselli model since the latter predicts that, as part of the equilibrating process of returns to capital, we would observe changes in the capital intensity distribution (or computer distribution) across plants in a parallel fashion with the rising wage and productivity dispersion. ${ }^{32}$

One possible reason that we did not find much evidence that changes in quantities matter is that we cannot adequately measure quality change in the capital equipment or computers. For example, while we use a computer investment measure that reflects relative differences within each year across plants to attempt to abstract from computer price deflator problems, it

${ }^{32}$ Caselli (1999) presents some empirical evidence of increased dispersion in capital intensities across four-digit industries. He finds that industries with increased capital intensity also exhibit an increase in wages. While these findings are clearly suggestive that there have been changes in the distribution of observables in a manner consistent with his model, the results reflect changes between four-digit industries. Since we find that the increase in between plant dispersion of wages (and productivity) is mostly a within industry phenomenon, these changes in the capital intensities across industries cannot account for much of the increased dispersion in wages. 
may be that the change in the quality of computers is such that a difference across plants in the amount of computer investment in 1992 implies something very different than the equivalent difference across plants in 1977 . Such quality effects imply that we might observe increases in the differentials between high and low computer investment per worker plants but not much contribution of the changes in the measured relative differences in the quantities of computers.

While the results are consistent with the theoretical predictions of the Kremer-Maskin and Caselli models, there are some caveats about ruling out other competing hypotheses. The finding that much of the increases in wage and productivity dispersion is within narrowly defined industries is evidence against explanations that involve between industry effects (such as shifts in product demand say due to changing trade patterns). However, it is possible that there are product demand shifts across plants in the same narrowly defined industry that could account for some aspects of our results. Consider, for example, a shift between products in the same fourdigit industry where plants in the same industry differ systematically in their product and skill mix. A shift towards products produced by high skilled workers and away from products produced by low skilled workers could yield rising wage dispersion across plants in the same industry and rising measured productivity dispersion. The latter could arise as the four-digit price deflators would not capture the relative price change within the industry implying systematic productivity mismeasurement across plants in the same industry. Even under this scenario one would have to account for the rising wage and productivity differentials across high and low capital intensive and high and low computer investment per worker plants. There might be a systematic relationship between product mix, skill mix, and technology used at the plant, but such a systematic relationship would begin to make this scenario closely linked to a broadly defined notion of skill biased technical change. 
One could likewise argue that some change in institutions would yield a pattern of within industry, between-plant increases in wage and productivity dispersion. Consider the possible impact of deunionization. Deunionization arguably may have yielded less wage compression and a relaxation of work rule constraints that could yield changes in wage and productivity dispersion across plants. However, again here, one would need to account for the fact that this rising wage and productivity dispersion is associated with rising wage and productivity differentials across high and low capital intensity plants and high and low computer investment per worker plants.

To conclude, we have documented that the rising overall wage dispersion in the U.S. economy is associated with rising wage and productivity dispersion across plants in the same narrowly defined industries and a substantial fraction of this rising wage and productivity dispersion is accounted for by rising wage and productivity differentials across high and low capital intensity plants and high and low computer investment per worker plants. Such findings are consistent with models of increased segregation by skill across plants and rising wage and productivity dispersion from skill-biased technical change that involves differential adoption of new technologies across plants. It may be that there are other models/hypotheses consistent with these findings but they will have to account for both the dominant role of between-plant effects and the important role of differences in capital intensity and computer intensity across plants. 


\section{Bibliography}

Autor, David, Lawrence Katz, and Alan Krueger, "Computing Inequality: Have Computers Changed the Labor Market?"Quarterly Journal of Economics, 113 (November 1998): 1169-1214.

Baily, Martin N., Charles Hulten, and David Campbell, "The Distribution of Productivity in Manufacturing Plants," Brookings Papers: Microeconomics, (1992): 187-268.

Bartelsman, Eric J. and Wayne Gray, "The NBER Manufacturing Productivity Database," NBER Technical Working Paper, No. 205 (October 1996).

Berman, Eli, John Bound, and Zvi Griliches, "Changes in the Demand for Skilled Labor Within U.S. Manufacturing Industries: Evidence from the Annual Survey of Manufacturing," Quarterly Journal of Economics, 109 (May 1994): 367-398.

Berndt, Ernst R. and Catherine J. Morrison, "High-Tech Capital Formation and Aggregate Economic Performance in U.S. Manufacturing Industries: An Exploratory Analysis," NBER Working Paper, (1992).

Bresnahan, Timothy, Erik Brynjolfsson, and Lorin Hitt, "Information Technology, Workplace Organization and the Demand for Skilled Labor: Firm-Level Evidence," mimeo (August 1998).

Caselli, Francesco, "Technological Revolutions," American Economic Review, 89 (March 1999): 78-102.

Davis, Steve J. and John Haltiwanger, "Wage Dispersion Between and Within U.S. Manufacturing Plants, 1963-1986," Brookings Papers on Economic Activity: Microeconomics, (1991): 115-200.

Davis, Steve J. and John Haltiwanger, "Employer Size and the Wage Structure in U.S. Manufacturing," Annales D'Economie et de Statistique, No. $41 / 42$ (1996): 323-367.

Doms, Mark, Timothy Dunne, and Kenneth Troske, "Workers, Wages, and Technology," Quarterly Journal of Economics, 112 (February 1997): 253-290.

Dunne, Timothy, John Haltiwanger, and Kenneth R. Troske. "Technology and Jobs: Secular Change and Cyclical Dynamics," Carnegie-Rochester Public Policy Conference Series, 46 (June 1997): 107-178.

Dwyer, Douglas, "Whittling Away at Productivity Dispersion," Center for Economic Studies Working Paper, No. 95-5 (1995). 
Goldin, Claudia and Robert Margo, "The Great Compression: The wage structure in the United States at Mid-Century," Quarterly Journal of Economics, 107 (February 1992): 1-34.

Greenan, Nathalie and Jacques Mairesse, "Computers and Productivity in France: Some Evidence," NBER Working Paper No. 5836 (November 1996).

Juhn, Chinhui, Kevin M. Murphy, and Brooks Pierce, "Wage Inequality and the Rise in the Return to Skill," Journal of Political Economy, 101 (June 1993): 410-42.

Katz, Lawrence F. and Kevin Murphy, "Changes in Relative Wages, 1963-1987: Supply and Demand Factors," Quarterly Journal of Economics, 107 (February 1992): 35-78.

Kremer, Michael and Eric Maskin, "Wage Inequality and Segregation By Skill, " NBER Working Paper, No. 5718 (August 1996).

Krueger, Alan, "How Computers Changed the Wage Structure: Evidence from Microdata, 198489," Quarterly Journal of Economics CVIII (February 1993): 33-60.

Lichtenberg, Frank R., "The Output Contributions of Computer Equipment and Personnel: A Firm-Level Analysis," NBER Working Paper, No. 4540 (November 1993).

Morrison, Catherine and Ernst R. Berndt, "Assessing the Productivity of Information Technology Equipment in U.S. Manufacturing Industries," NBER Working Paper, No. 3582 (January 1991).

Oliner, Stephen and Daniel Sichel, "Computers and Output Growth Revisited: How Big is the Puzzle?" Brookings Paper on Economic Activity, 2, (1994).

Olley, Steven and Ariel Pakes, "The Dynamics of Productivity in the Telecommunications Equipment Industry," Econometrica, 64 (November 1996): 1263-1297.

Siegel, Donald, "The Impact of Computers on Manufacturing Productivity Growth: A MultipleIndicators, Multiple-Causes Approach," Review of Economic Statistics, 79, (February 1997): 68-78.

Troske, Kenneth R., "A Note on Computer Investment in U.S. Manufacturing," mimeo, Center for Economic Studies, U.S. Bureau of the Census, (1996). 


\section{Data Appendix}

\section{A. Combining Household and Establishment Survey Data -- Measurements Issues}

Several measurement error issues arise in combining information from household and establishment surveys. Since Davis and Haltiwanger (1991) provide an extensive discussion of these issues in this context, we review only the most salient issues here. First, unlike Davis and Haltiwanger (1991), we incorporate auxiliary establishments into our analysis using data from the Standard Statistical Establishment List (SSEL) which includes the universe of all establishments in each year. Therefore, our establishment-level data contain wage information for all manufacturing workers.

Second, like Davis and Haltiwanger $(1991,1996)$, we must confront the difficulties associated with the fact that we have hours data only for production workers. We impute hoursper-worker for nonproduction workers in our augmented LRD as follows. Using the CPS, we calculate the ratio of hours-per-worker for production and nonproduction workers at the two-digit level. Using this ratio, and the measured hours-per-worker for production workers at the plantlevel in the LRD, we impute the hours-per-worker for nonproduction workers in a plant by requiring the ratios be the same in the CPS and the LRD. ${ }^{33}$ Since this is at best a crude procedure, we further adjust the LRD means and variances of hourly wages for nonproduction workers so that the ratio of the LRD to CPS mean of hourly wages for nonproduction workers equals the corresponding ratio for production workers. ${ }^{34}$ We carry out this latter adjustment at the two-digit industry level (i.e., we do not require this ratio to hold at the plant-level).

While this methodology for combining household and establishment level data may be imprecise in a given year (especially for nonproduction workers), the time series changes in the respective contributions should be robust as long as the measurement error problems are stable over time. As will become clear, there is considerable evidence in favor of this argument.

Table Al presents summary statistics for hourly wages for all workers, nonproduction workers, and production workers for selected years. The first two columns are based upon the CPS, the second two columns are from the LRD, the next two columns are from the LRD supplemented with auxiliary establishments, and the last two columns are from the LRD augmented to incorporate the comparability adjustment described above (and also including the auxiliary establishments). ${ }^{35}$ All statistics are in 1987 dollars and are on an hours-weighted basis so that CPS and LRD tabulations are in principle directly comparable.

${ }^{33}$ For auxiliary establishments which, by definition, contain no production workers, we use the average number of hours worked by production workers in a given two-digit industry in the CPS to impute hours worked in these establishments.

${ }^{34}$ This adjustment imposes no restrictions on the ratios of the variances of wages of production and nonproduction workers.

${ }^{35}$ The between-within decompositions use the augmented LRD (columns 7-8), the JMP decompositions use the raw LRD (columns 3-4). 
It is apparent from Table A1 that the LRD yields higher average hourly wages for all workers in each year and that this is primarily driven by substantially higher average hourly wages for nonproduction workers (for example, the LRD with auxiliary establishments included has average nonproduction wages that are more than $10 \%$ higher than those in the CPS) ${ }^{36}$ However, the time series patterns in the mean wages across the different data sets are quite similar. The five year growth rates are similar across the CPS and the LRD for all manufacturing workers, nonproduction workers, and particularly for production workers. In addition, the time series patterns for average hourly wages for the different versions of the LRD exhibit similar patterns. The close correspondence in the time series patterns across the CPS and LRD provides further support for the argument that one can compare the CPS and the LRD to learn about the sources of time series changes in the patterns of wages.

While the means should in principle match up across the CPS and the LRD, the standard deviations of hourly wages may exhibit quite different patterns. The CPS standard deviation will reflect both within-plant and between-plant differences in wages across workers while the LRD standard deviation will only reflect between-plant differences in wages across workers.

${ }^{36}$ Note that Davis and Haltiwanger $(1991,1996)$ also found higher average hourly earnings in the LRD and that this was driven primarily from nonproduction workers. One important factor is likely the crude imputation procedure for hours for nonproduction workers which motivates the further adjustment of nonproduction hourly wages in the LRD. Note that we have also discovered some differences between the results reported here and those in Davis and Haltiwanger $(1991,1996)$. Davis and Haltiwanger (1996) also augmented the LRD with auxiliary establishments for an analysis of wage dispersion in 1982. Their tabulations of 1982 wages from the CPS and the LRD for 1982 yield a substantially smaller gap between CPS and LRD hourly wages. The sources of these differences likely reflect some other differences between the data files used in the respective analyses. Davis and Haltiwanger use public use CPS files with top coded wages and adjust for top coding in the manner developed by Katz and Murphy (1992). In contrast, we are using internal CPS files without top coded wages. Interestingly, we find somewhat lower average wages using the internal CPS files than the public use files adjusted for top coding. Another source of difference is the auxiliary establishment $\mathrm{CAO}$ files. Davis and Haltiwanger use auxiliary establishment files processed during the economic censuses while we use auxiliary establishment files directly from the SSEL. The files from the economic censuses have been more thoroughly edited which may be important. In practice, we find higher average wages in our auxiliary establishment files from the SSELs than the auxiliary establishment files from the economic censuses. We created our auxiliary establishment files from the SSELs as opposed to the economic censuses since the latter are available only every five years. We decided not to mix census-based auxiliary establishment files and SSEL-based auxiliary establishment files in non-census years to avoid changes in measurement methodology over time. 
Accordingly, the CPS standard deviation exceeds the LRD standard deviation in each year for all workers and for each worker type. Interestingly, however, the time series increase in the CPS standard deviation of hourly wages over the 1977-92 period is mimicked by similar time series increases in the LRD standard deviation. Further, the fourth column in Table A.1 indicates that the increase in between-plant wage dispersion for all manufacturing plants is associated with an increase in between-plant wage dispersion for operating manufacturing establishments.

\section{B. JMP Time Series Analysis}

The decomposition of overall time series changes in dispersion are presented in the form of a sequence of four panel graphs: Figures A1 through A5. In each of these figures, Panel A presents the overall 90-10 dispersion for the four years 1977, 1982, 1987, and 1992. Panel B presents the contribution of changes in the distribution of observable characteristics. Panel C presents the contribution due to changes in the differentials associated with the observable characteristics (the $\beta$ 's), and Panel D presents the contribution due to changes in the distribution of unobservable factors. In panel B, C, and D, the solid line is for the model that contains all variables, the mixed (short-long) dashed line is for a model that contains only computer investment per worker in the regression, and the short dashed line is for a model that contains only the capital-labor ratio. The components in these three panels are measured as deviations from their mean.

Although there is a secular increase in labor productivity dispersion from 1977-92, there is a pronounced decline in labor productivity dispersion from 1977-82 followed by a sharp increase in dispersion from 1982 through 1992. Neither changes in the distribution of capital intensity or computers is associated with this cyclical variation in labor productivity dispersion. This implication is evident from the cyclical nature of the contribution of the unobservables when only computers or capital intensity is included in the model. However, changes in the distribution of characteristics and changes in the distribution of $\beta$ 's for some other plant observables do help account for this cyclical variation. Apparently, there are plant observable characteristics other than computer investment or capital intensity for which the labor productivity dispersion associated with these characteristics is diminished during business cycle slumps.

Unlike labor productivity, there is relatively little cyclical variation in the between-plant dispersion of wages or nonproduction labor share. Observable plant characteristics for fixed $\beta$ 's yield some modest procyclicality in wage dispersion but this is offset by the effects of these characteristics and by the unobservables.

A final point regarding the aggregate JMP exercises concerns the timing of the changes in dispersion. Figures (A1-A5) depict the time-series changes in dispersion that are derived from the JMP analysis. In the case of productivity, productivity dispersion actually falls in the 1977 to 1982 period and then rises rapidly, whereas wage dispersion and nonproduction labor share dispersion rise throughout the period. In fact, for both production worker wages and the nonproduction labor share (Figure A3 and A5), dispersion is increasing most rapidly in the same period where productivity dispersion is falling. The differences in timing raise some basic questions about the role of common factors accounting for the changes in the dispersion of wages and productivity. There may be several factors at work: e.g., differences in the cyclicality of wages and productivity that impact dispersion or differences in the timing of the response of 
wages and productivity to common factors. These differences in timing are an area for further work. 
Table 1: Between-Plant and Within-Plant Components of Hourly Wage Variance.

\begin{tabular}{|c|c|c|c|c|}
\hline & $\frac{1977}{(1)}$ & $\frac{1982}{(2)}$ & $\frac{1987}{(3)}$ & $\frac{1992}{(4)}$ \\
\hline \multicolumn{5}{|c|}{ A. Measures of Dispersion } \\
\hline Total Wage Variance & 43.18 & 42.83 & 58.01 & 61.13 \\
\hline \multicolumn{5}{|l|}{ Coefficient of Variation: } \\
\hline Total & .58 & .56 & .64 & .68 \\
\hline Within plant & .43 & .36 & .45 & .45 \\
\hline Within plant, $\mathrm{PW}$ & .22 & .19 & .25 & .21 \\
\hline Within plant, NPW & .47 & .32 & .42 & .38 \\
\hline Between plant & .40 & .43 & .45 & .51 \\
\hline Between plant, PW & .41 & .44 & .45 & .47 \\
\hline Between plant, NPW & .44 & .48 & .49 & .56 \\
\hline \multicolumn{5}{|c|}{ B. Shares of Dispersion } \\
\hline$\alpha V^{P}$ & .34 & .34 & .27 & .21 \\
\hline$\alpha V_{w}^{p}$ & .08 & .05 & .07 & .04 \\
\hline$\alpha V_{B}{ }^{p}$ & .26 & .29 & .20 & .17 \\
\hline$\alpha \mathrm{V}_{\mathrm{BPI}}^{\mathrm{P}}$ & .18 & .20 & .15 & .13 \\
\hline$\alpha \mathrm{V}_{\mathrm{BI}}^{\mathrm{p}}$ & .08 & .08 & .05 & .04 \\
\hline$(1-\alpha) \mathrm{V}^{\mathrm{N}}$ & .58 & .58 & .63 & .68 \\
\hline$(1-\alpha) V_{w}{ }^{N}$ & .31 & .18 & .27 & .21 \\
\hline$(1-\alpha) V_{B}^{N}$ & .27 & .40 & .36 & .47 \\
\hline$(1-\alpha) \mathrm{V}_{\mathrm{BPI}}^{\mathrm{N}}$ & .25 & .37 & .32 & .42 \\
\hline$(1-\alpha) V_{B I}^{N}$ & .03 & .03 & .04 & .05 \\
\hline$\alpha(1-\alpha)\left(\mathrm{W}^{\mathrm{P}}-\mathrm{W}^{\mathrm{N}}\right)^{2}$ & .08 & .08 & .10 & .11 \\
\hline$\alpha$ & .68 & .61 & .60 & .57 \\
\hline
\end{tabular}

(1) Measures of Dispersion: PW refers to production workers, NPW refers to nonproduction workers.

(2) Shares of Dispersion: The variance decomposition is based on equation (2) in the text. Superscript denotes worker-type $(\mathrm{P}=$ production workers, $\mathrm{N}=$ nonproduction workers), subscript denotes component-type ( $\mathrm{W}=$ within plants, $\mathrm{B}=$ between plants, $\mathrm{BPI}=$ between plants, within industries, $\mathrm{BI}=$ between industries).

(3) All figures are in 1987 dollars and are computed on an hours-weighted basis. As described in the text, the tabulations are based on data from the LRD and CPS. 
Table 2: Kremer-Maskin Segregation Index

\begin{tabular}{|c|c|c|c|}
\hline & $\frac{\text { All Workers }}{(1)}$ & $\frac{\text { Production Workers }}{(2)}$ & $\frac{\text { Nonproduction Workers }}{(3)}$ \\
\hline 1977 & 0.48 & 0.77 & 0.47 \\
\hline 1982 & 0.59 & 0.84 & 0.69 \\
\hline 1987 & 0.50 & 0.76 & 0.57 \\
\hline 1992 & 0.56 & 0.83 & 0.69 \\
\hline
\end{tabular}

Note: The Kremer-Maskin (1996) Segregation Index is $\mathrm{V}_{\mathrm{b}}^{\mathrm{i}} / \mathrm{V}_{\mathrm{T}}^{\mathrm{i}}$, where i indexes worker type: all workers, production workers or nonproduction workers, $\mathrm{b}$ indicates the variance is between plant, while $\mathrm{T}$ indicates the total variance. The index is constructed using augmented LRD data. 


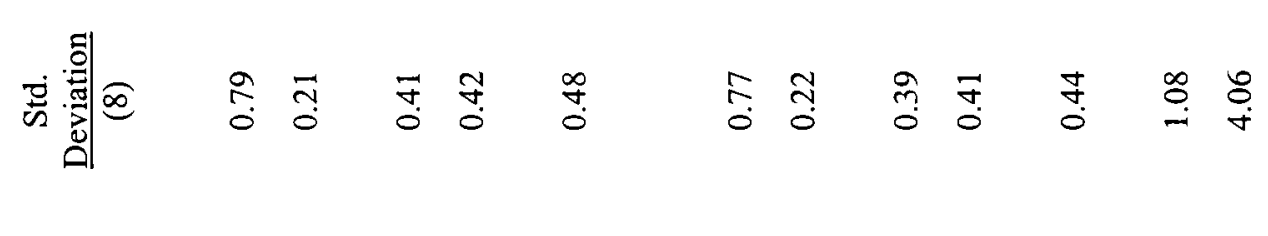

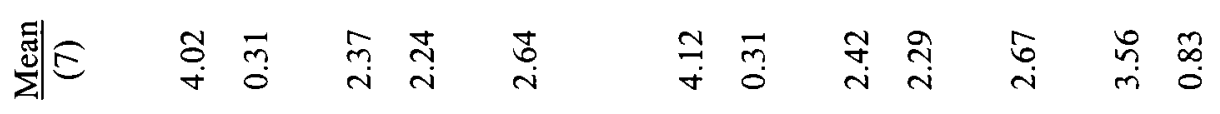

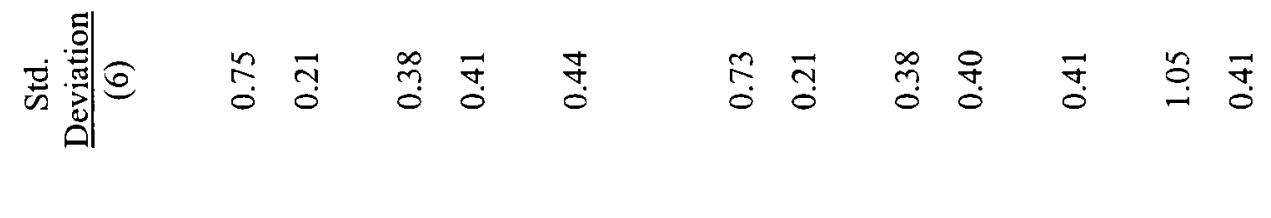

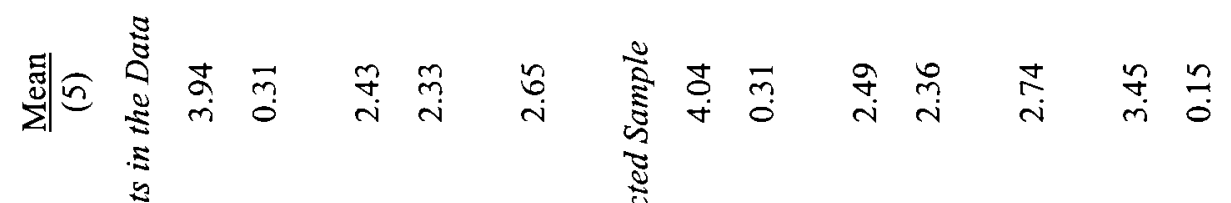

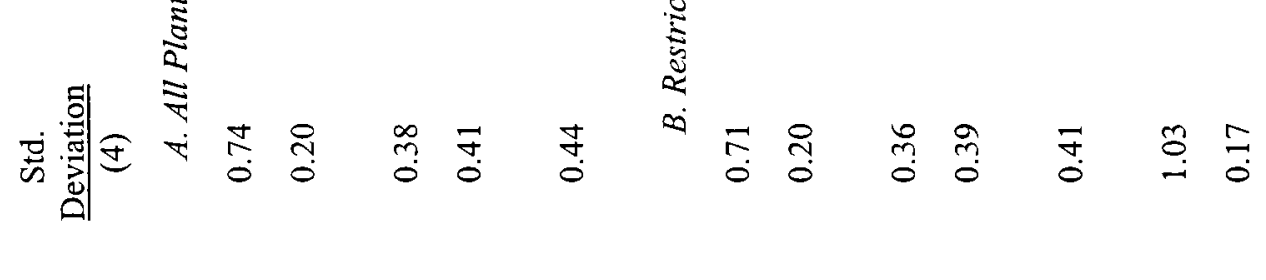

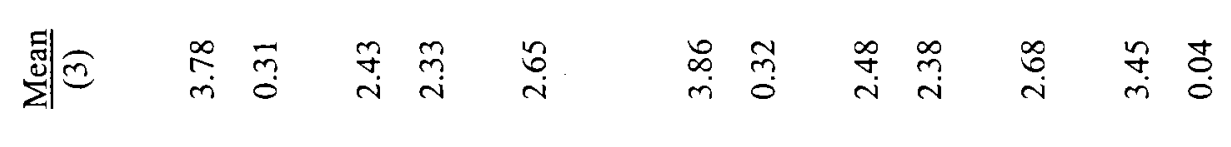

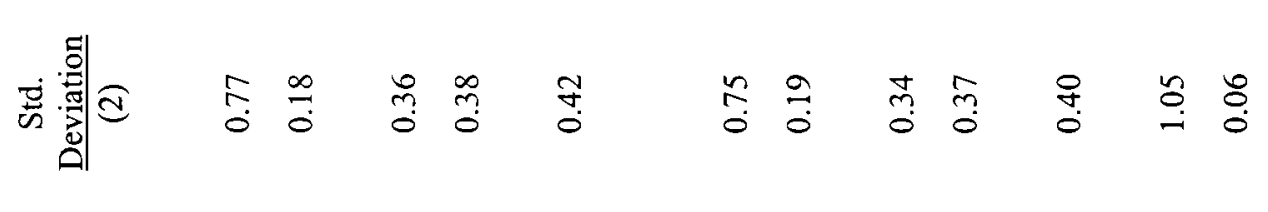

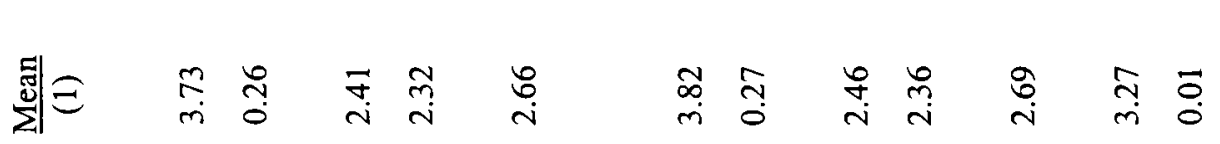

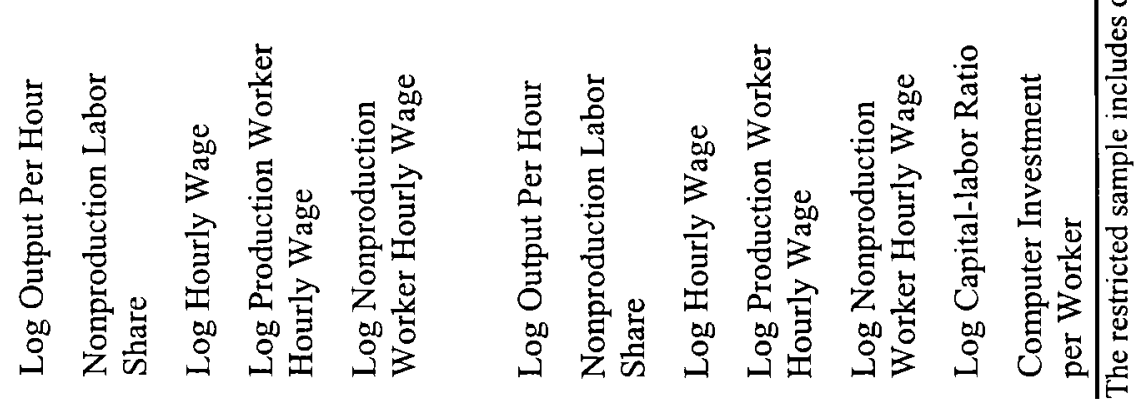


Table 4: Summary Measures of the Distribution of Regression Coefficients By Two-Digit Industry on Computer and Capital Intensity for Main Specification

\begin{tabular}{|c|c|c|c|c|c|}
\hline Variable & $\frac{1977}{(1)}$ & $\frac{1982}{(2)}$ & $\frac{1987}{(3)}$ & $\frac{1992}{(4)}$ & $\frac{\text { Pooled }}{(5)}$ \\
\hline \multicolumn{6}{|c|}{ A. Productivity } \\
\hline Computers Mean & -.0016 & .0028 & .0088 & .0211 & .0013 \\
\hline Computers Range & $-.002, .006$ & $-.009, .033$ & $-.010, .108$ & $-.011, .133$ & $-.009, .017$ \\
\hline Capital-Labor Mean & .2285 & .2336 & .2635 & .2361 & .2441 \\
\hline Capital-Labor Range & $.064, .549$ & $.087, .431$ & $.137, .449$ & $.136, .464$ & $.132,436$ \\
\hline \multicolumn{6}{|c|}{ B. Hourly Wage } \\
\hline Computers Mean & .0012 & .0022 & .0072 & .0160 & .0023 \\
\hline Computers Range & $-.003, .007$ & $-.002, .013$ & $-.001, .036$ & $.000, .056$ & $.000, .009$ \\
\hline Capital-Labor Mean & .0860 & .1038 & .1046 & .0975 & .1017 \\
\hline Capital-Labor Range & $.032, .147$ & $.035, .127$ & $.059, .150$ & $.041, .170$ & $.059, .147$ \\
\hline \multicolumn{6}{|c|}{ C. Production Worker Wage } \\
\hline Computers Mean & .0005 & -.0007 & .0003 & .0070 & .0006 \\
\hline Computers Range & $-.005, .006$ & $-.013, .008$ & $-.015, .023$ & $-.014, .046$ & $-.004, .007$ \\
\hline Capital-Labor Mean & .0856 & .1052 & .1101 & .0994 & .1031 \\
\hline Capital-Labor Range & $.016, .148$ & $.056, .162$ & $.061, .169$ & $.066, .160$ & $.065, .138$ \\
\hline \multicolumn{6}{|c|}{ D. Non-Production Worker Wage } \\
\hline Computers Mean & .0014 & .0020 & .0086 & .0142 & .0026 \\
\hline Computers Range & $-.006, .016$ & $-.007, .013$ & $-.004, .034$ & $-.003, .071$ & $.000, .017$ \\
\hline Capital-Labor Mean & .0541 & .0648 & .0567 & .0588 & .0607 \\
\hline Capital-Labor Range & $.004, .124$ & $-.013, .141$ & $-.043, .113$ & $.001, .165$ & $-.001, .123$ \\
\hline \multicolumn{6}{|c|}{ E. Non-Production Share } \\
\hline Computers Mean & .0017 & .0049 & .0083 & .0132 & .0027 \\
\hline Computers Range & $-.001, .010$ & $-.001, .018$ & $.000, .021$ & $.000, .048$ & $.000, .008$ \\
\hline Capital-Labor Mean & .0038 & .0075 & .0060 & .0087 & .0088 \\
\hline Capital-Labor Range & $-.063, .040$ & $-.036, .047$ & $-.039, .045$ & $-.027, .059$ & $-.031, .048$ \\
\hline
\end{tabular}


Table 5: Adjusted R-Squared Statistics from Productivity, Wage, and Share Regressions.

\begin{tabular}{|c|c|c|c|c|c|}
\hline & $\frac{1977}{(1)}$ & $\frac{1982}{(2)}$ & $\frac{1987}{(3)}$ & $\frac{1992}{(4)}$ & $\frac{\text { Pooled }}{(5)}$ \\
\hline \multicolumn{6}{|c|}{ A. Productivity } \\
\hline All Controls & .6844 & .6291 & .6207 & .6172 & .6044 \\
\hline Computers Only & .0198 & .0253 & .0361 & .0639 & .0442 \\
\hline Capital Only & .3393 & .3633 & .3911 & .3693 & .3794 \\
\hline \multicolumn{6}{|c|}{ B. Hourly Wage } \\
\hline All Controls & .6567 & .6304 & .6291 & .5849 & .6077 \\
\hline Computers Only & .0254 & .0458 & .0698 & .0650 & .0345 \\
\hline Capital Only & .2718 & .2978 & .2912 & .2886 & .2844 \\
\hline \multicolumn{6}{|c|}{ C. Production Worker Wage } \\
\hline All Controls & .6640 & .6433 & .6205 & .5732 & .6090 \\
\hline Computers Only & .0150 & .0346 & .0463 & .0471 & .0277 \\
\hline Capital Only & .2955 & .3068 & .3002 & .3044 & .3010 \\
\hline \multicolumn{6}{|c|}{ D. Non-Production Worker Wage } \\
\hline All Controls & .2398 & .1992 & .2296 & .2258 & .2003 \\
\hline Computers Only & .0090 & .0146 & .0197 & .0239 & .0136 \\
\hline Capital Only & .0598 & .0666 & .0591 & .0858 & .0683 \\
\hline \multicolumn{6}{|c|}{ E. Non-Production Share } \\
\hline All Controls & .5098 & .5152 & .5682 & .5245 & .5169 \\
\hline Computers Only & .0597 & .0770 & .1307 & .0817 & .0662 \\
\hline Capital Only & .0538 & .0641 & .0671 & .0502 & .0345 \\
\hline
\end{tabular}

Notes: All Controls includes computers per worker, capital per worker, and size classes interacted with two-digit industry; fourdigit industry; and region. Computers only includes computers per worker interacted with two-digit industry. Capital only includes capital per worker interacted with two-digit industry. 
Table 6: JMP Full Distributional Accounting Components for Changes in 90-10 Differentials

\begin{tabular}{lccccc}
\hline & $\begin{array}{c}\text { Labor } \\
\text { Productivity }\end{array}$ & $\frac{\text { Hourly Wage }}{(1)}$ & $\frac{\text { Production Wages }}{(3)}$ & $\frac{\text { Nonprod Wages }}{(4)}$ & $\begin{array}{c}\text { Nonprod. } \\
\text { Labor Share }\end{array}$ \\
$\begin{array}{l}\text { Total 1977- } \\
\text { 1992 Change }\end{array}$ & .161 & .114 & .090 & .128 & .108 \\
Observables & -0.018 & -0.003 & -0.019 & \\
Beta's & 0.112 & 0.066 & 0.073 & -0.015 & 0.028 \\
Unobservables & 0.067 & 0.053 & 0.036 & 0.039 & 0.047 \\
& \multicolumn{7}{c}{ A. Full Model Decomposition } \\
Observables & 0.031 & 0.015 & 0.009 & 0.104 & 0.033 \\
Beta's & 0.112 & 0.053 & 0.052 & 0.008 & 0.012 \\
Unobservables & 0.017 & 0.048 & 0.028 & 0.042 & 0.025 \\
& & C. Model with Only the Capital-Labor Ratio & & 0.071 \\
Observables & 0.039 & 0.019 & 0.017 & 0.078 & 0.009 \\
Beta's & 0.106 & 0.098 & 0.090 & 0.067 & 0.004 \\
Unobservables & 0.016 & -0.001 & -0.017 & 0.052 & 0.091 \\
\hline
\end{tabular}




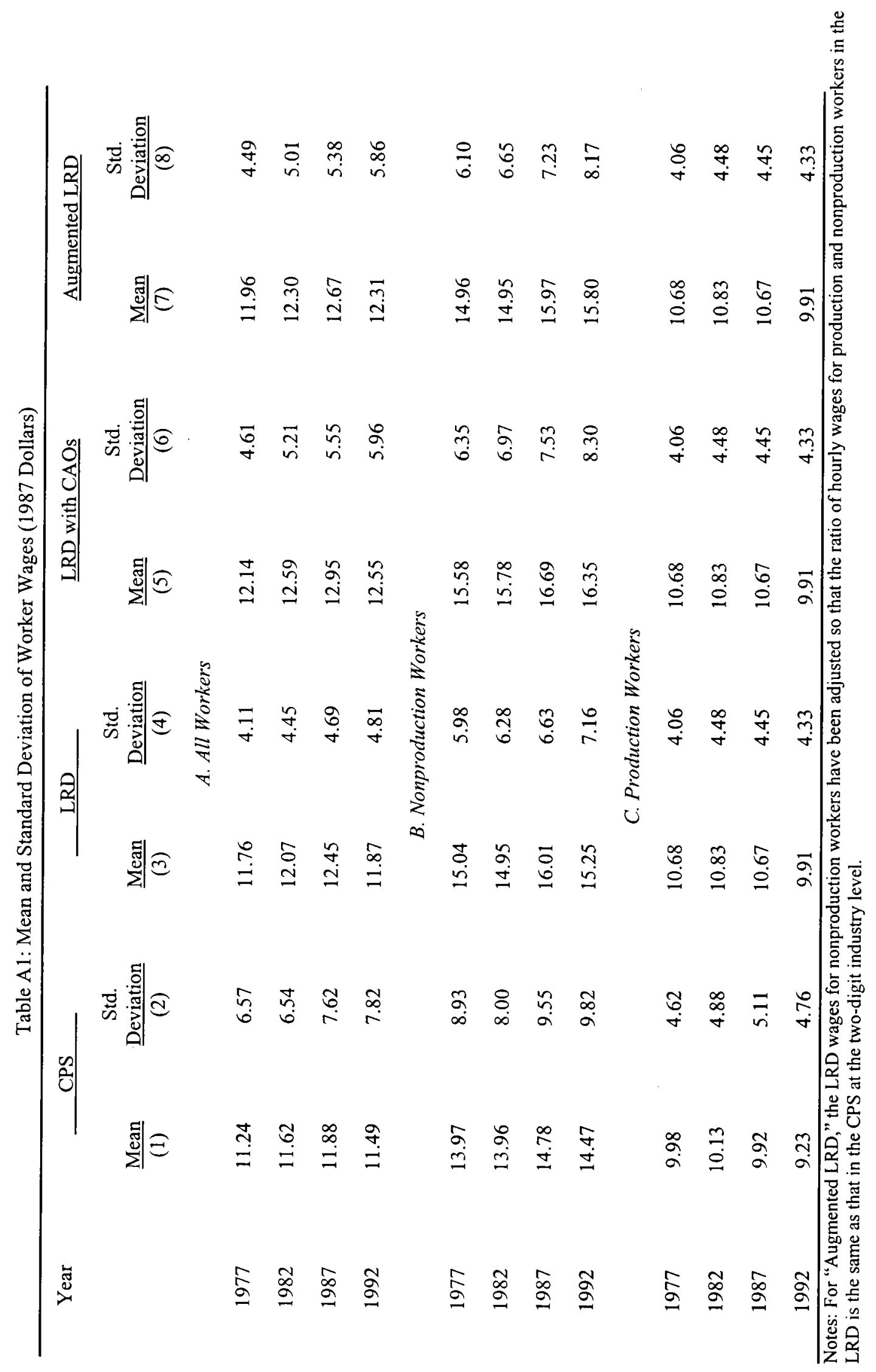


Figure 1: Coefficient of Variation Within-Plant, Between-Plant

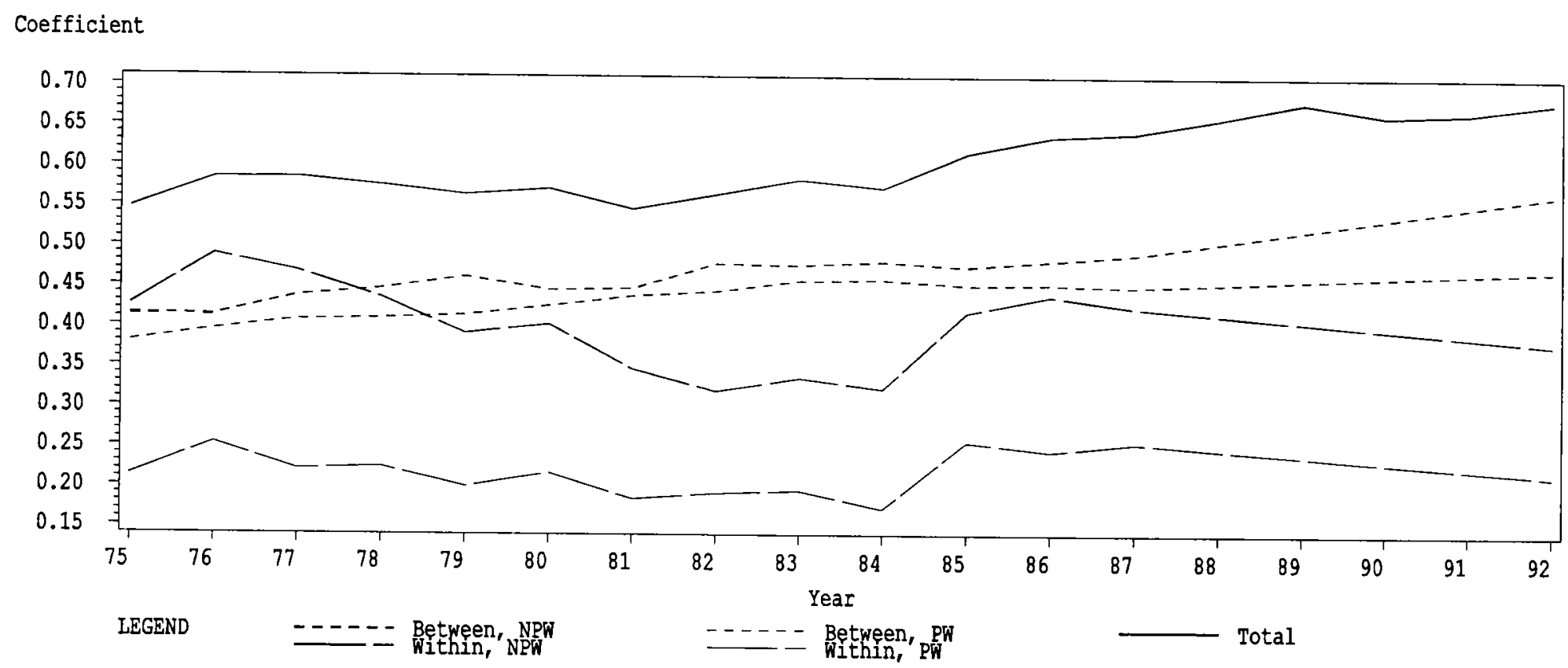

Note: 1988-1991 components are interpolated 
Figure 2: Dispersion in Log Worker Wages and Productivity

A. Wage Dispersion

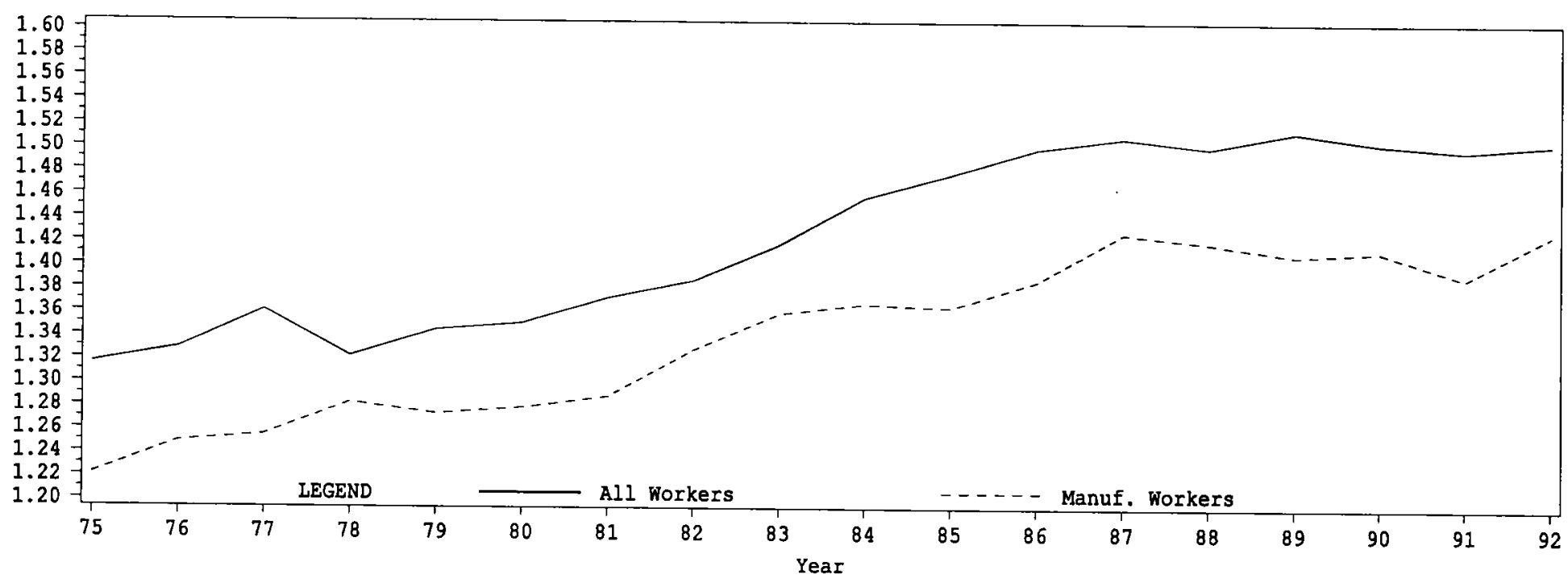

B. Between-Plant Productivity Dispersion in Manufacturing

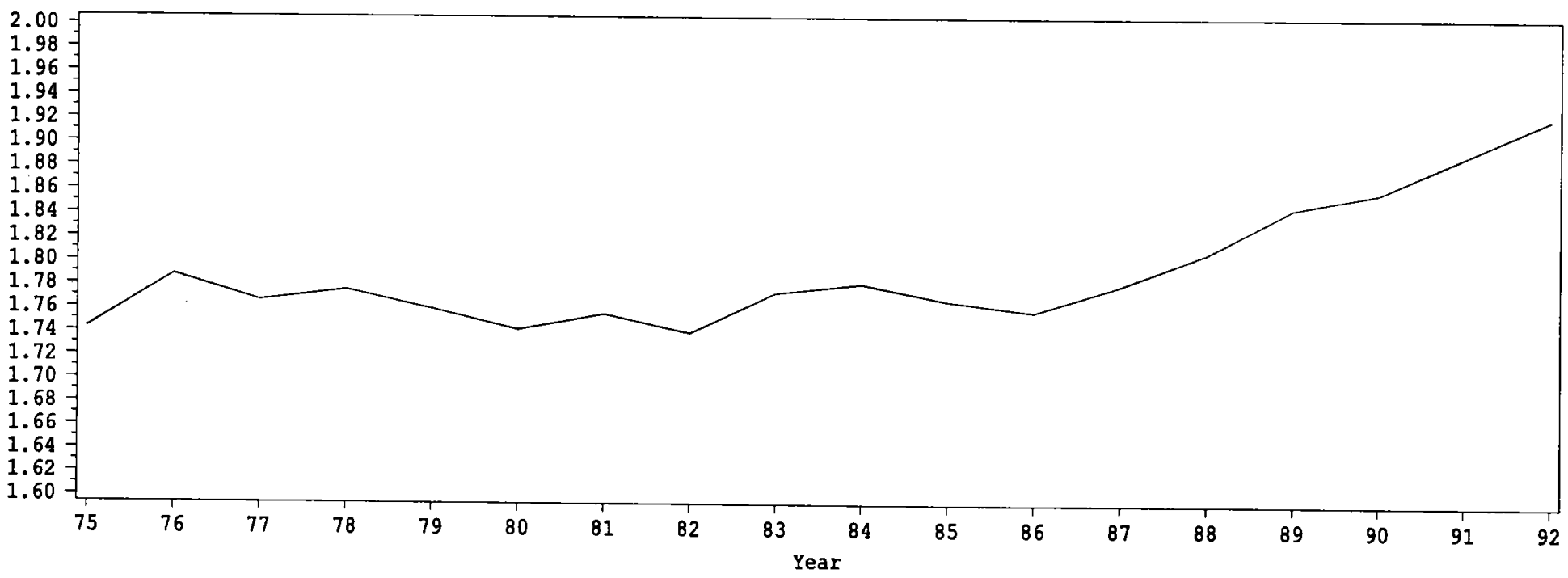

Source: Internal Census Bureau March CPS files and LRD 
Figure 3: Between Plant Wage and Productivity Dispersion - By Industry

A. Hourly Wage

Change in Hourly Wage Dispersion

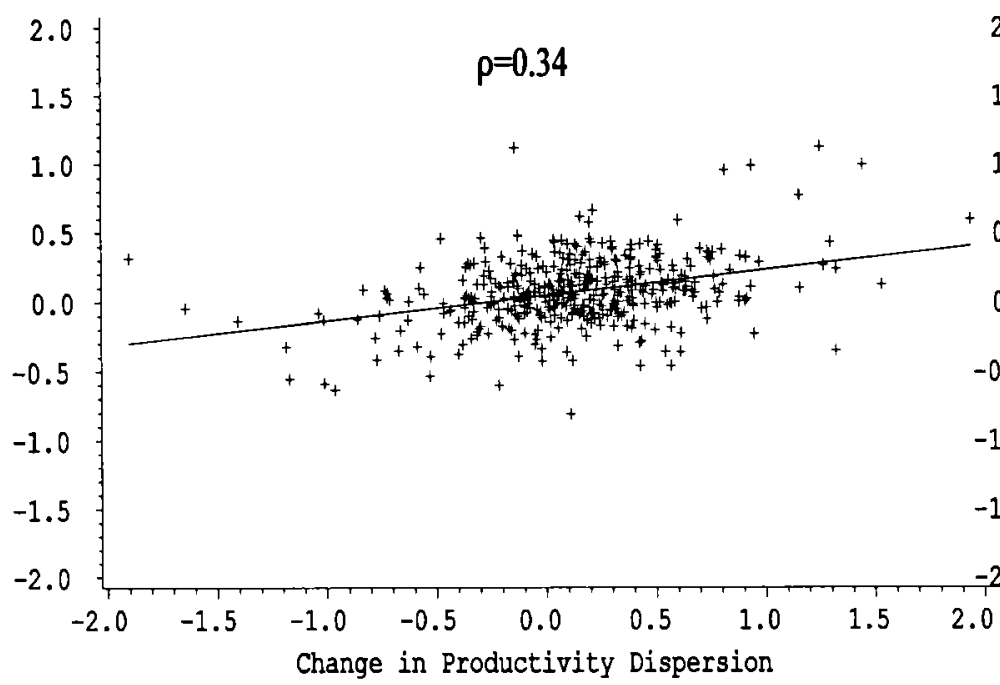

C. Nonproduction Worker Wage Change in Nonproduction Worker Wage Dispersion

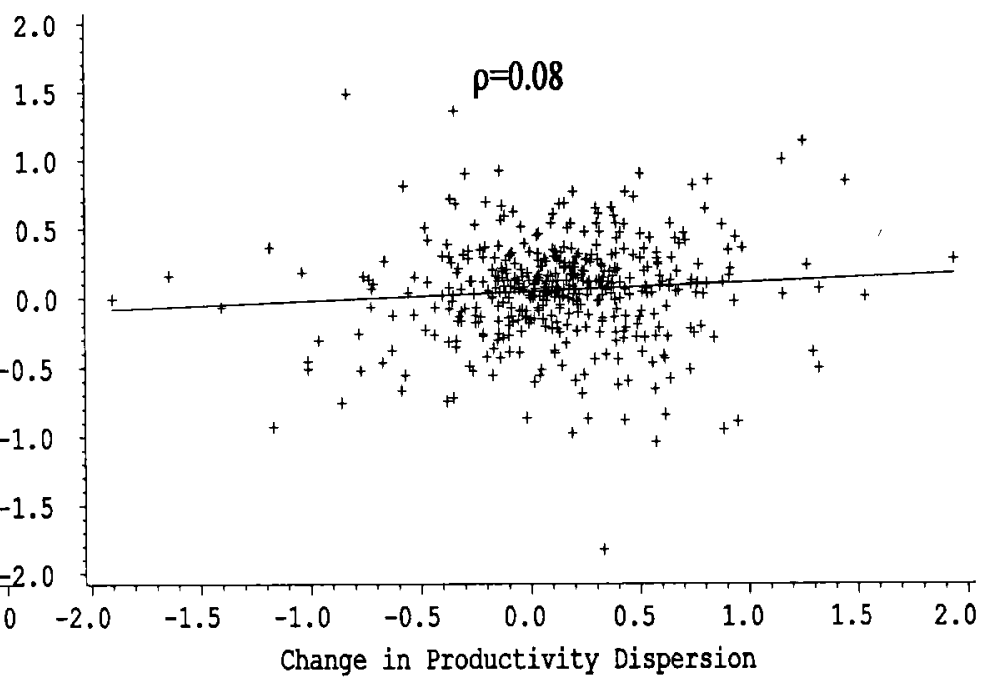

B. Production Worker Wage Change in Production Worker Wage Dispersion

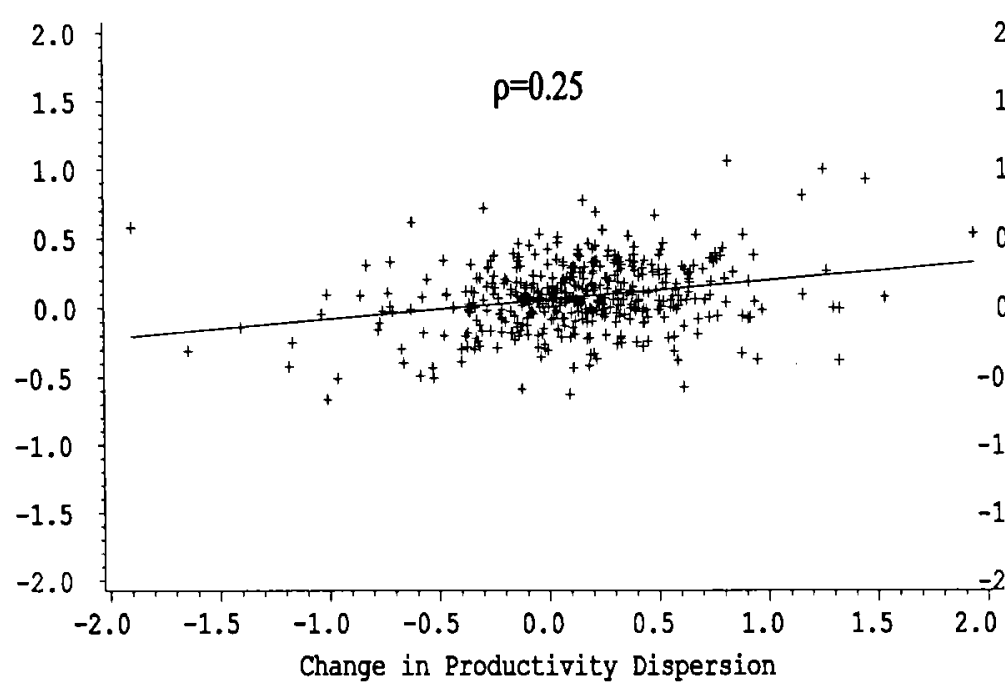

Dispersion is 90-10 for 1977-92 changes.
D. Nonproduction Labor Share Change in Nonproduction Labor Share Dispersion

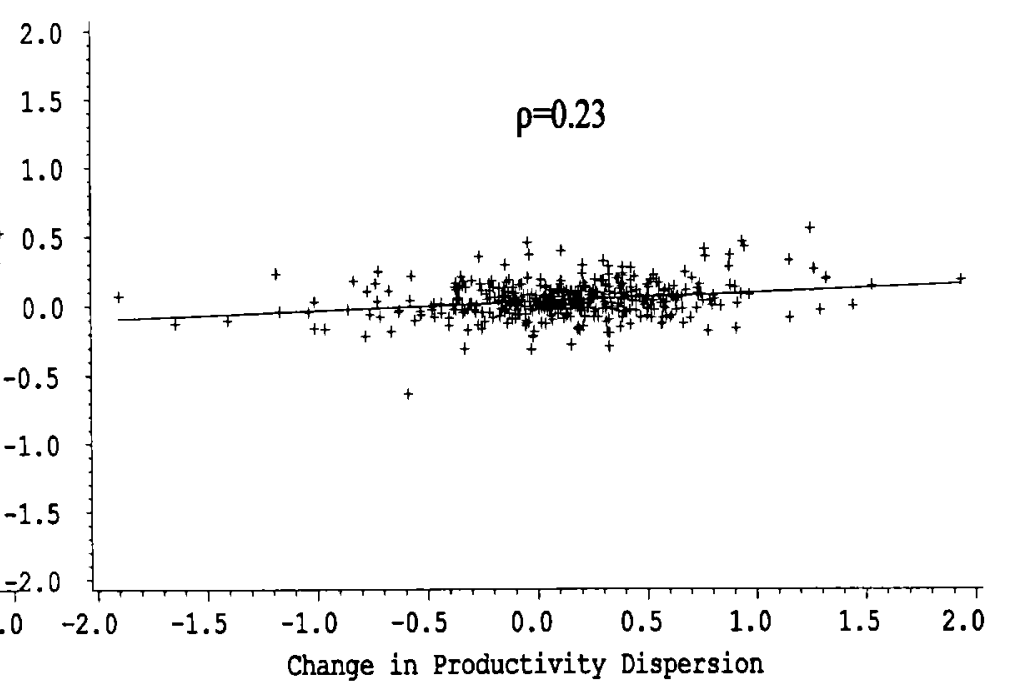


Figure 4: Between Plant JMP Decompositions, All Controls - By Industry

A. Predicted and Actual Productivity Dispersion Observables

Change in Predicted Dispersion

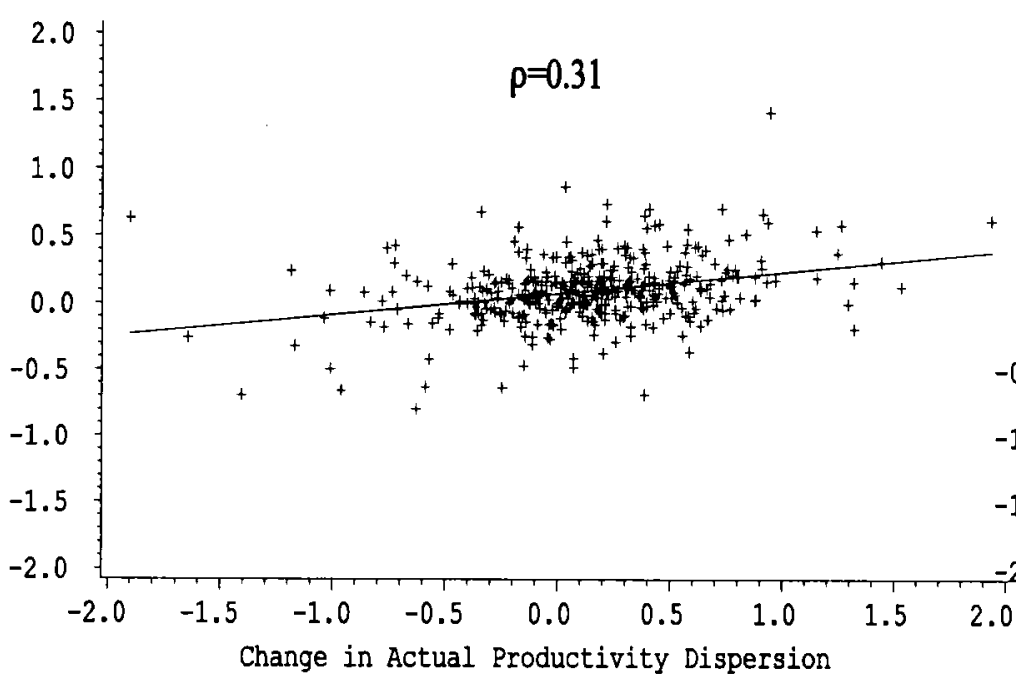

C. Predicted Hourly Wage and Productivity Dispersion Observables Change in Hourly Wage Dispersion

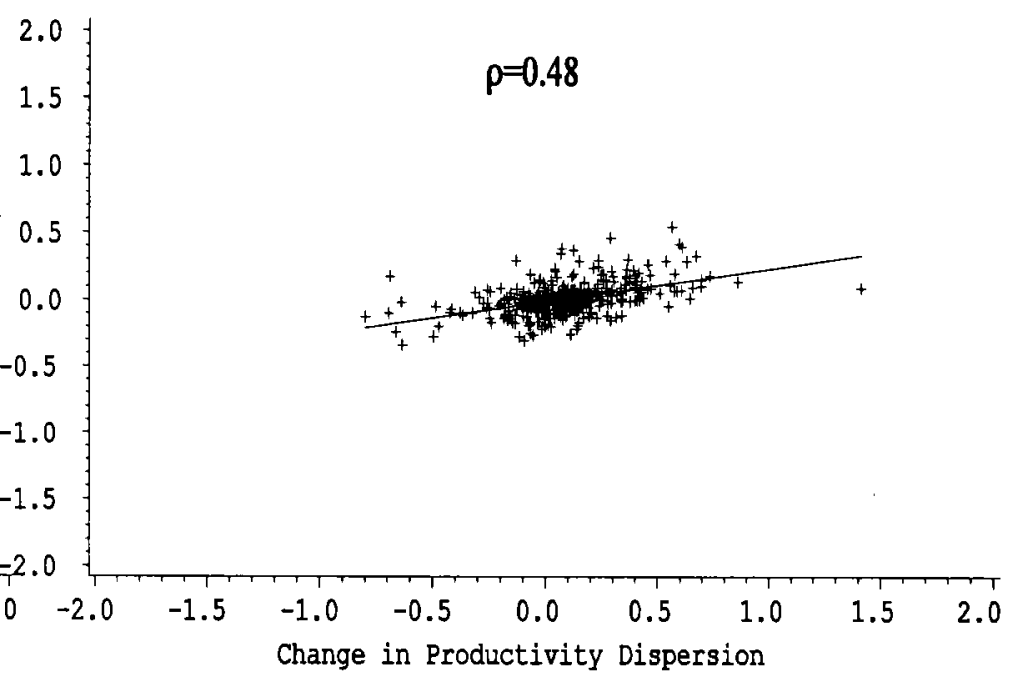

B. Predicted and Actual Hourly Wage Dispersion Observables

Change in Predicted Dispersion

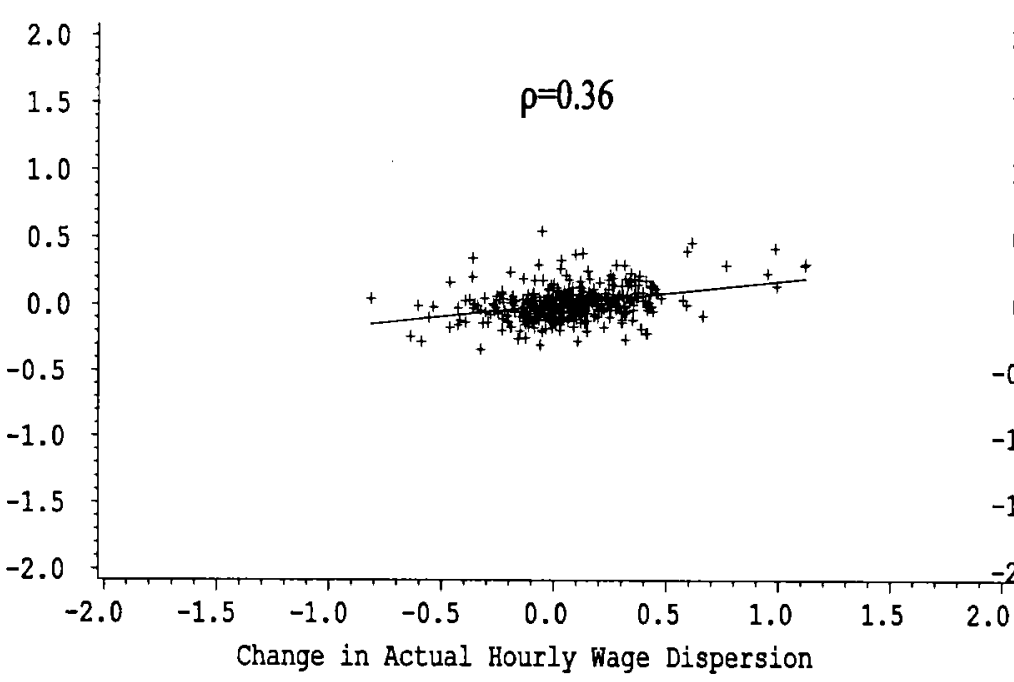

Dispersion is $90-10$ for $1977-92$ changes.
D. Hourly Wage and Productivity Dispersion Unobservables

Change in Hourly Wage Dispersion

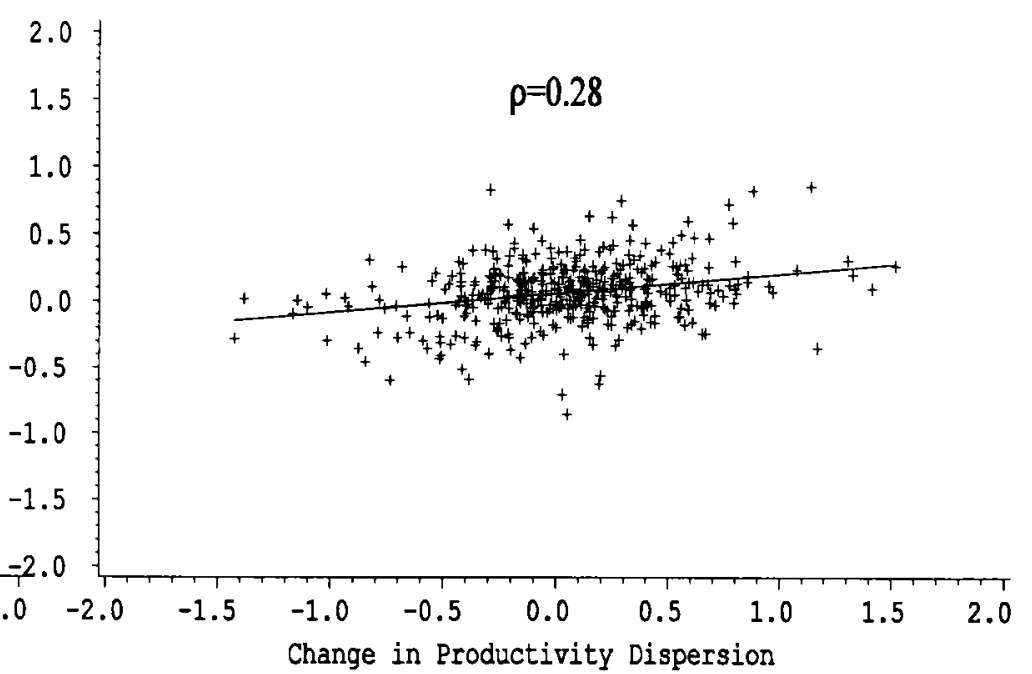


Figure 5: Between Plant JMP Decompositions, Only Computers - By Industry

A. Predicted and Actual Productivity Dispersion observables

Change in Predicted Dispersion

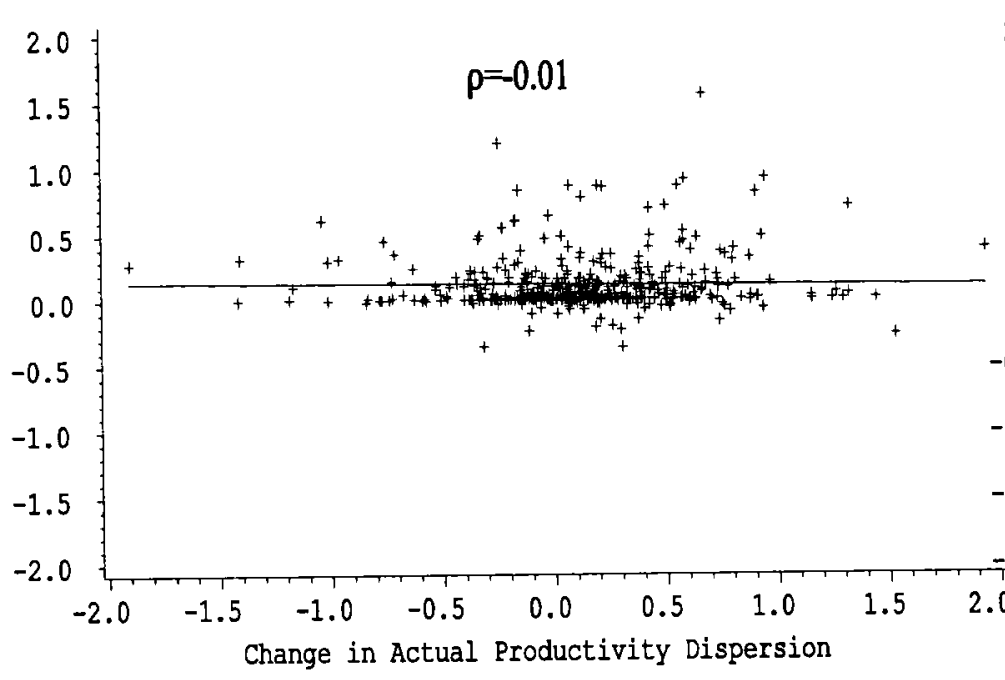

B. Predicted and Actual Hourly Wage Dispersion observables

Change in Predicted Dispersion

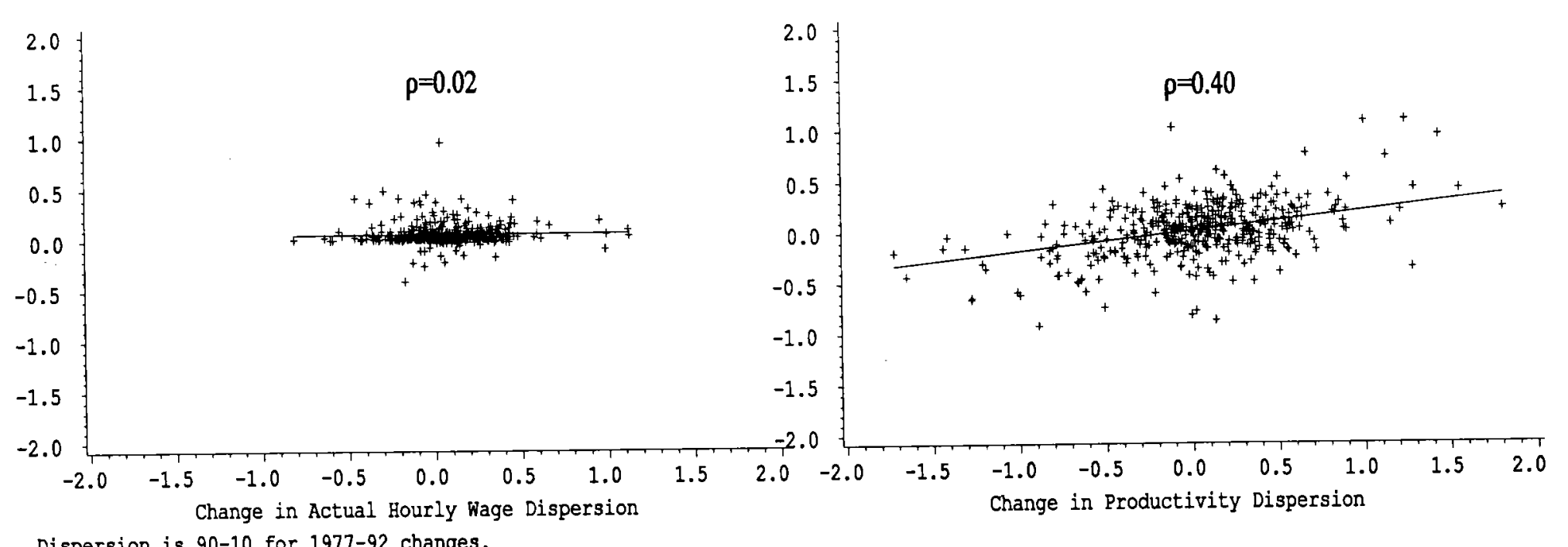
Observables

Change in Hourly Wage Dispersion

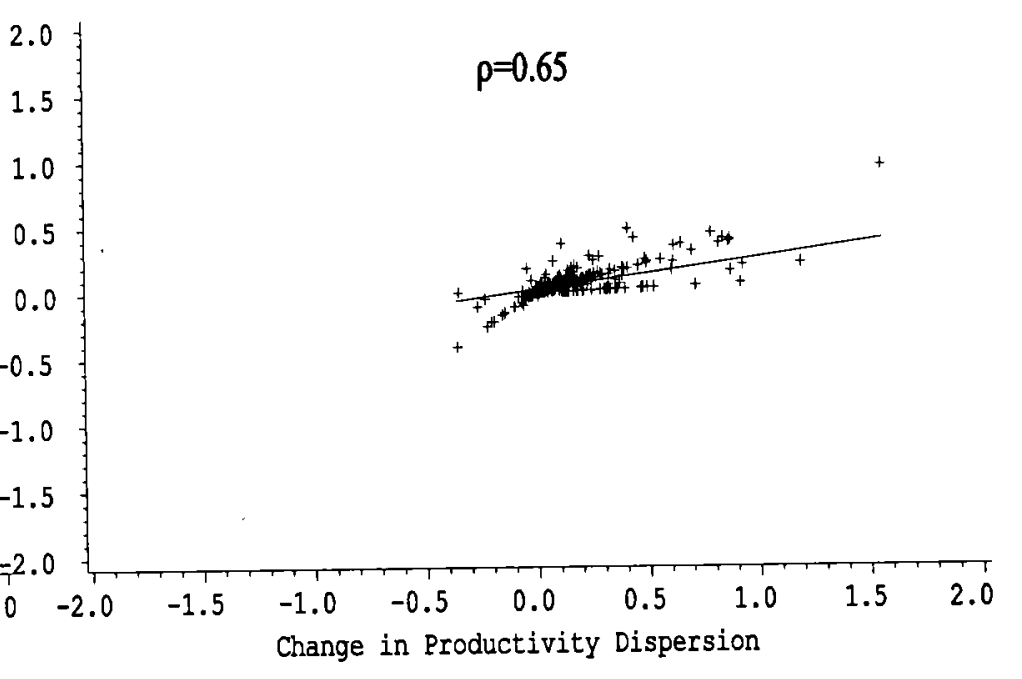

D. Hourly Wage and Productivity Dispersion Unobservables

Change in Hourly Wage Dispersion

C. Predicted Hourly Wage and Productivity Dispersion 
Figure 6: Between Plant JMP Decompositions, Only Capital -- By Industry

A. Predicted and Actual Productivity Dispersion Observables

Change in Predicted Dispersion

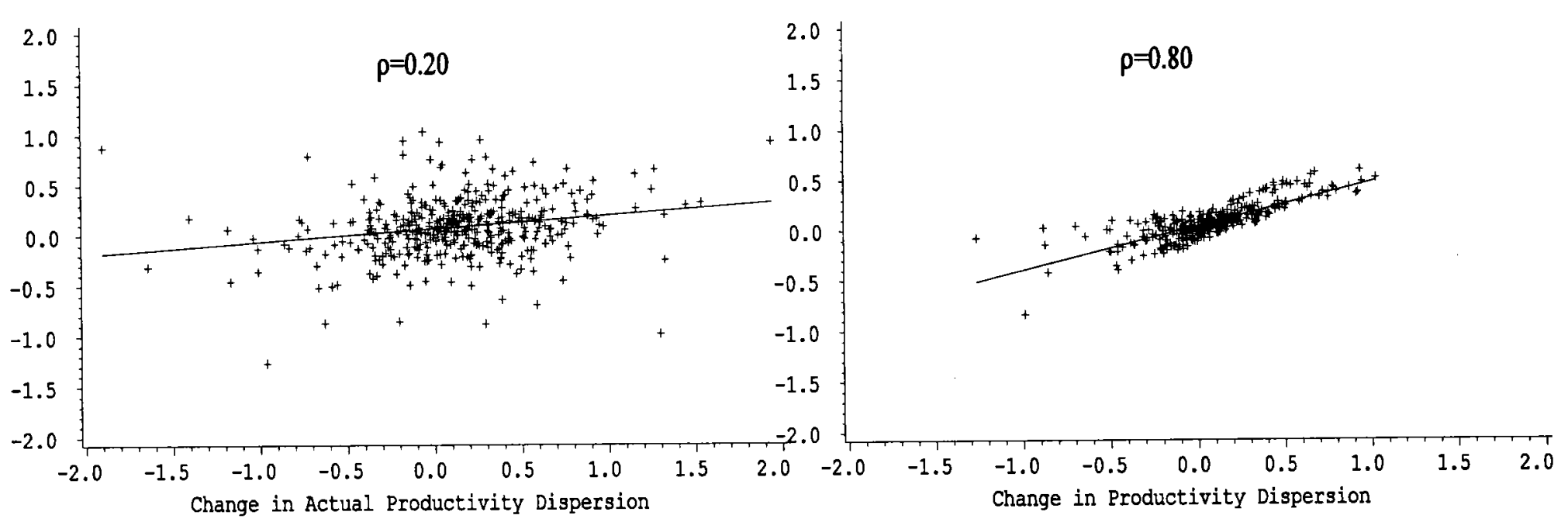

C. Predicted Hourly Wage and Productivity Dispersion observables

Change in Hourly Wage Dispersion
B. Predicted and Actual Hourly Wage Dispersion observables

Change in Predicted Dispersion
D. Hourly Wage and Productivity Dispersion Unobservables

Change in Hourly Wage Dispersion

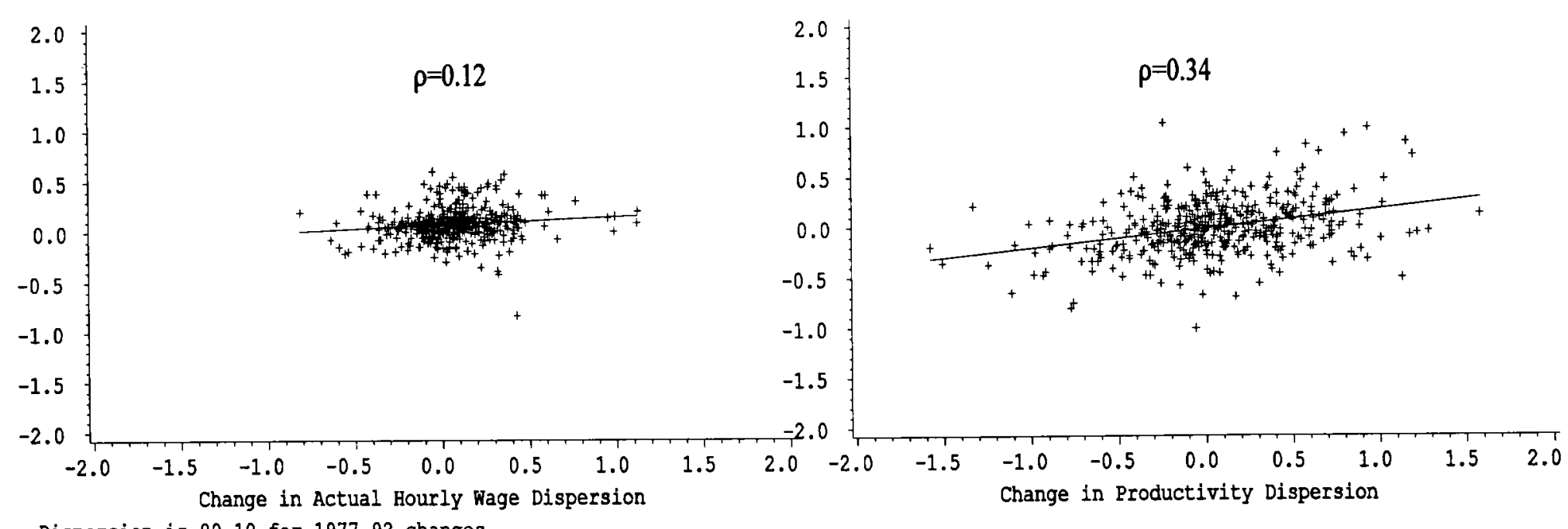

Dispersion is 90-10 for 1977-92 changes. 
Figure A1: Time Series Behavior of Between Plant Dispersion of Log Output Per Hour
A. Actual 90-10 Dispersion
B. Observable Characteristics
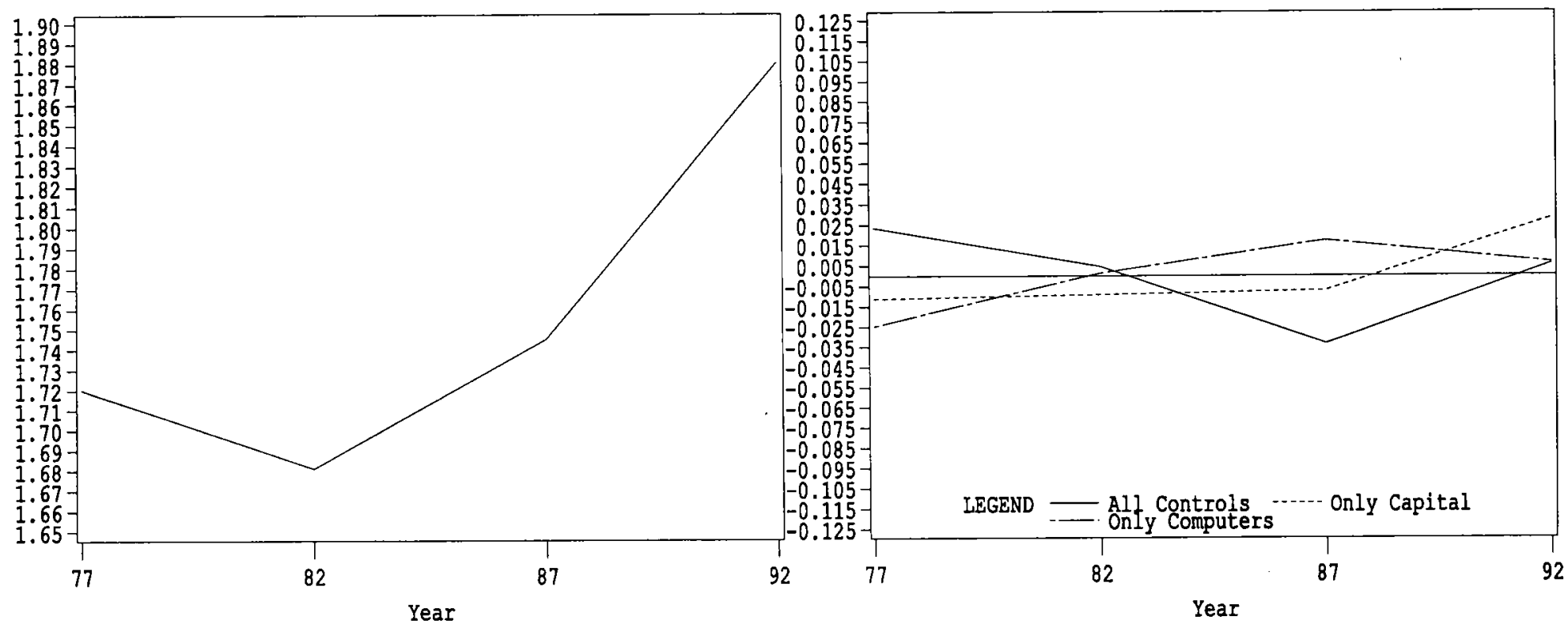

C. Observable Betas

D. Unobservables
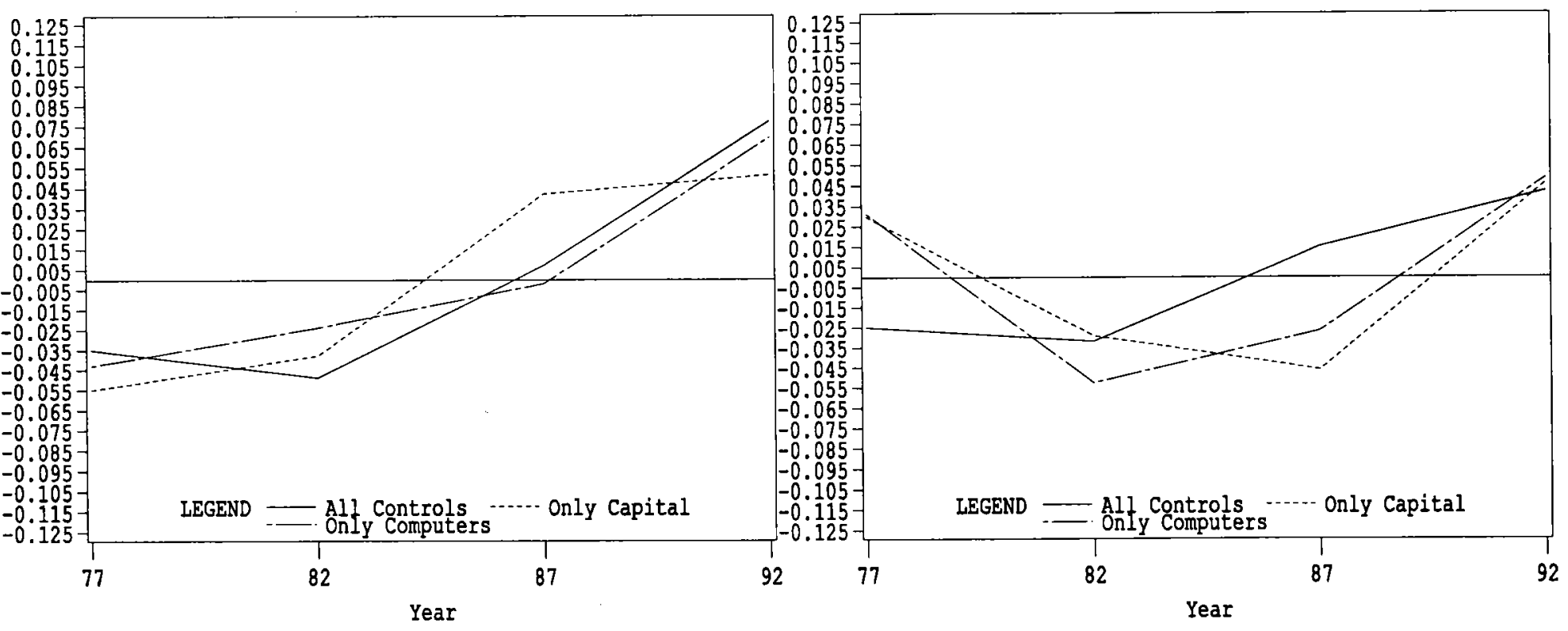
Figure A2: Time Series Behavior of Between Plant Dispersion of Log Hourly Wage
A. Actual 90-10 Dispersion
B. Observable Characteristics
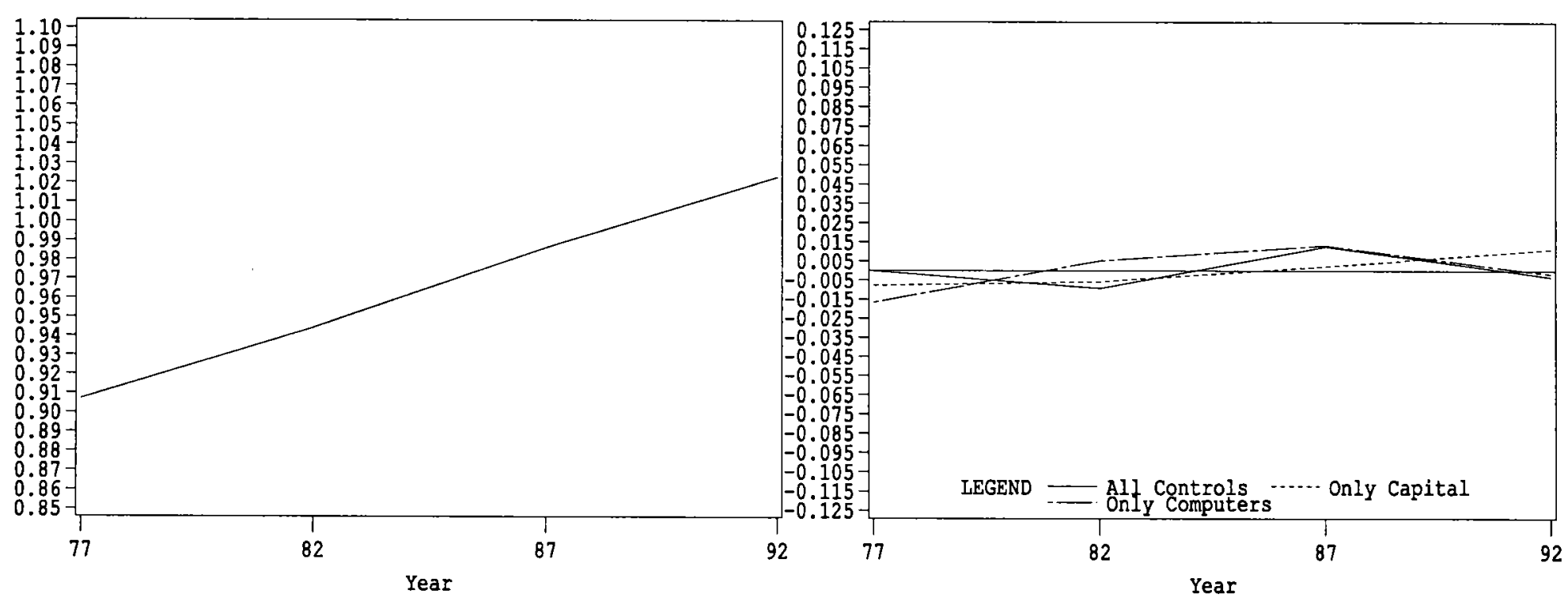

C. Observable Betas

D. Unobservables
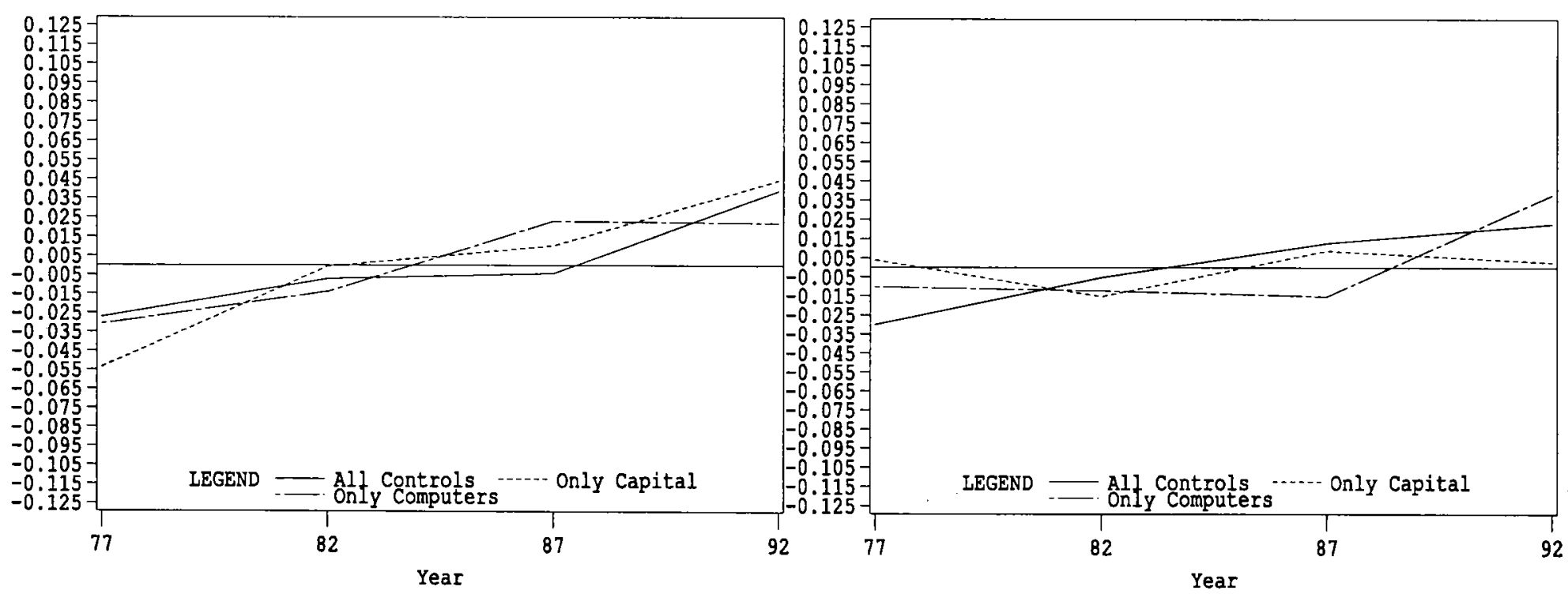
Figure A3: Time Series Behavior of Between Plant Dispersion of Log Production Worker Hourly Wage

A. Actual 90-10 Dispersion

B. Observable Characteristics
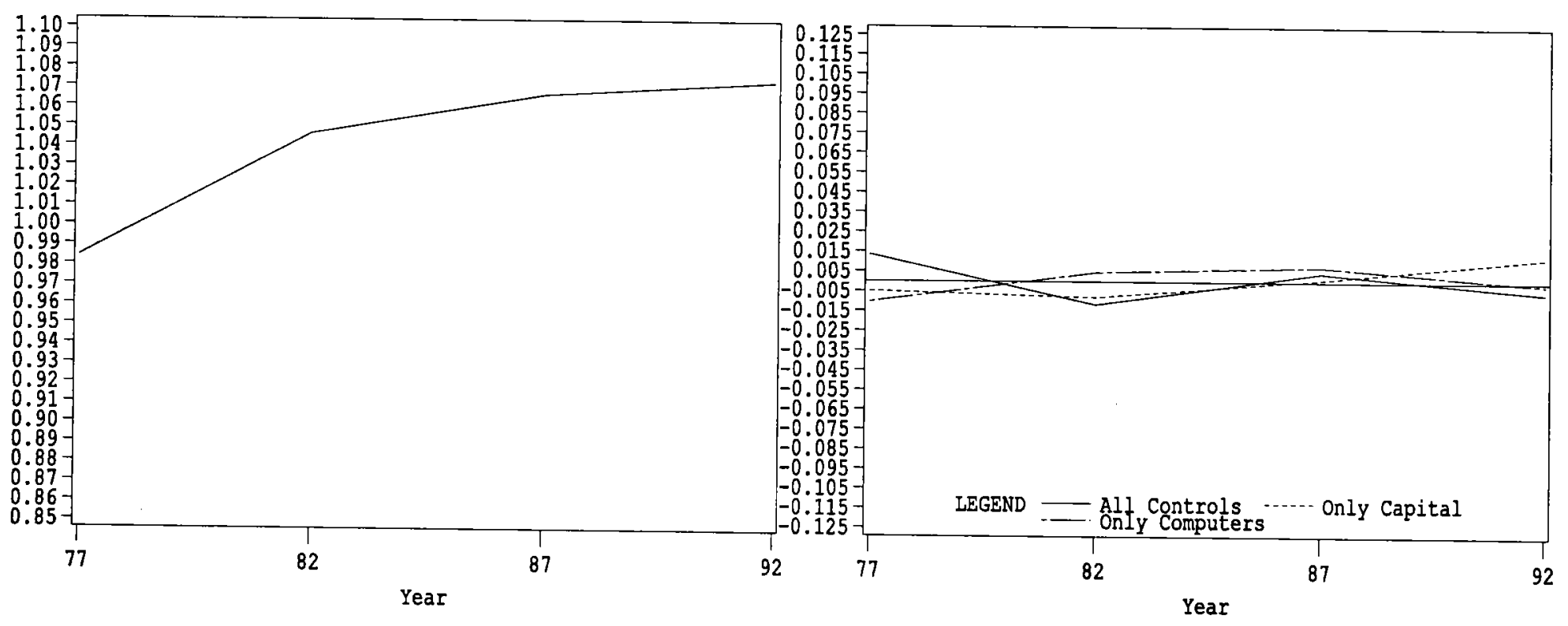

C. Observable Betas

D. Unobservables
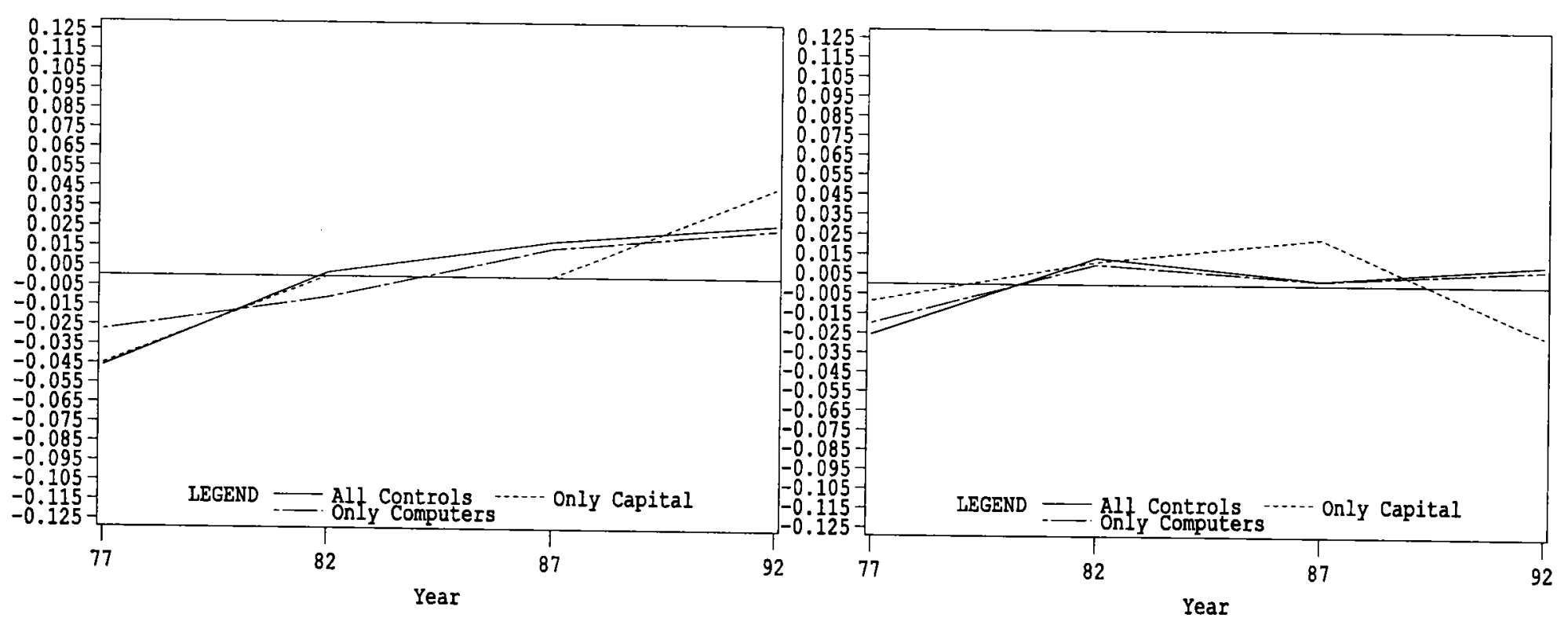
Figure A4: Time Series Behavior of Between Plant Dispersion of Log Nonproduction Worker Hourly Wage

A. Actual 90-10 Dispersion

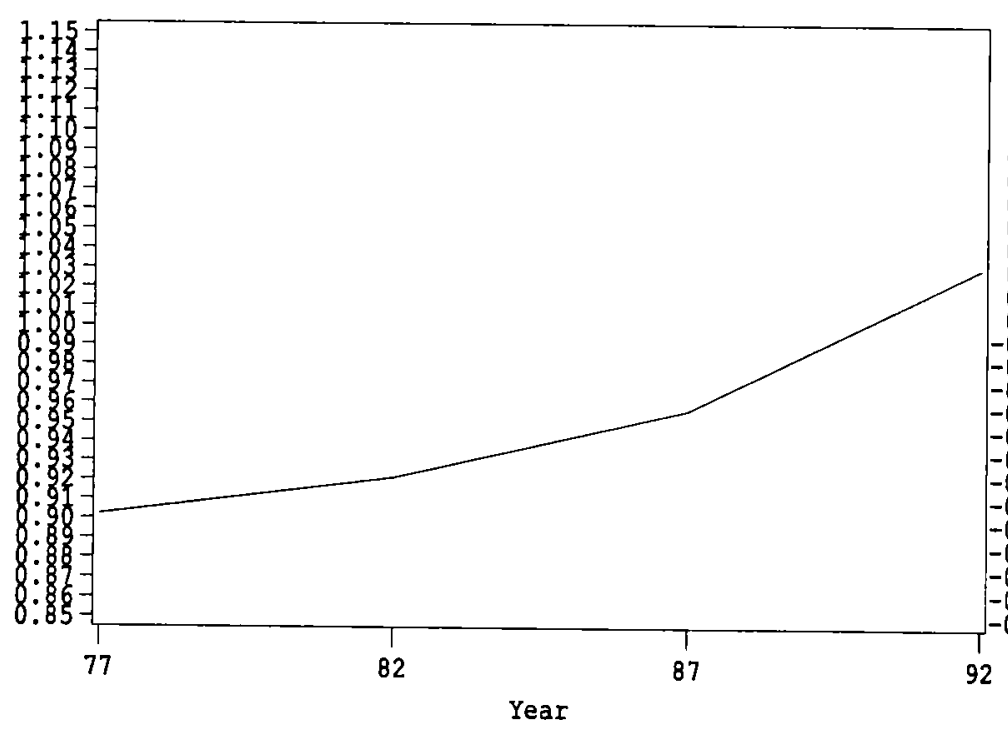

B. Observable Characteristics

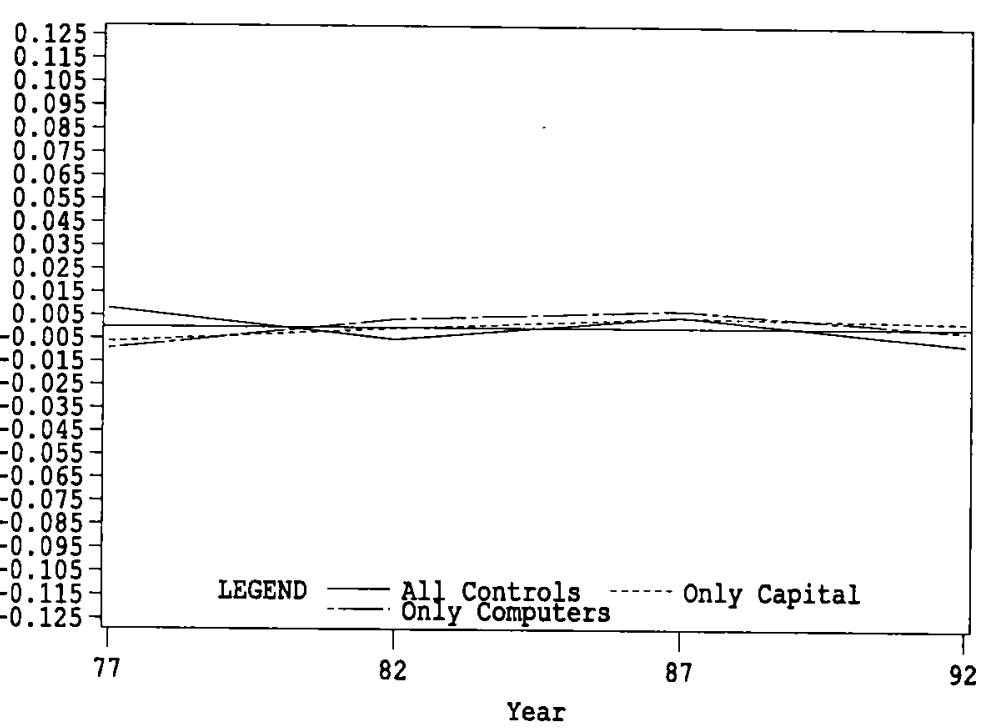

D. Unobservables
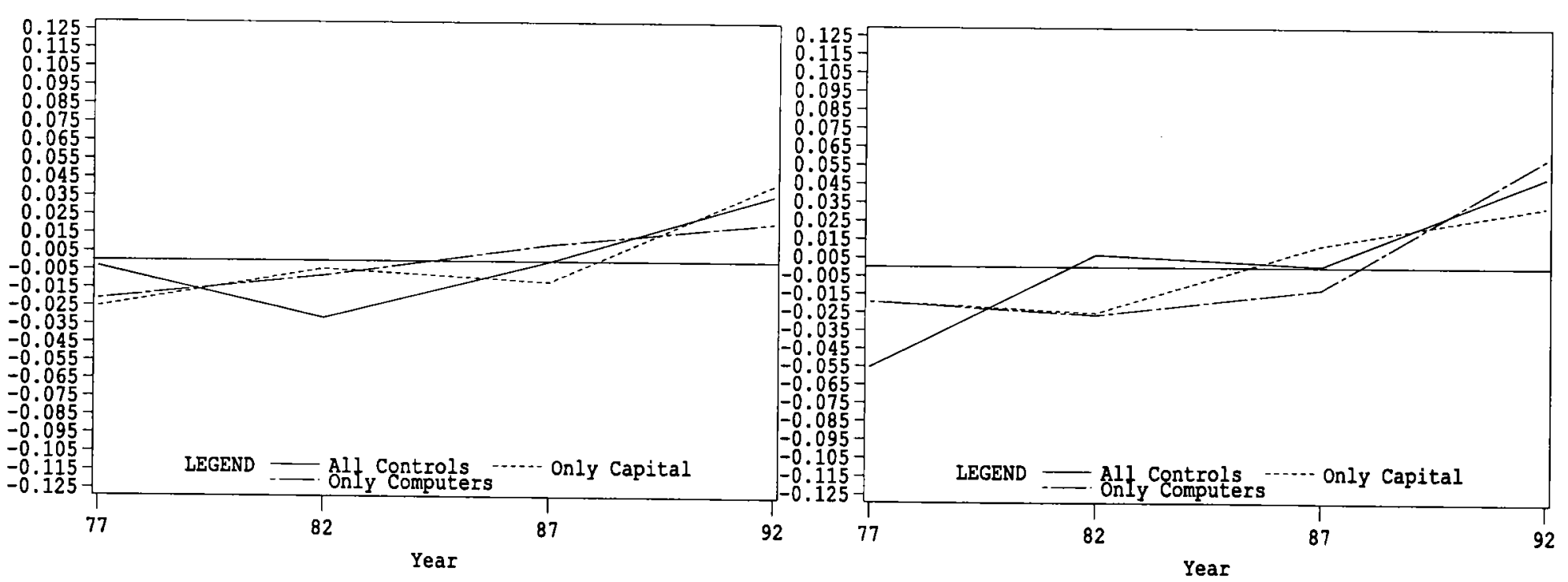
Figure A5: Time Series Behavior of Between Plant Dispersion of Log Nonproduction Labor Share

A. Actual 90-10 Dispersion

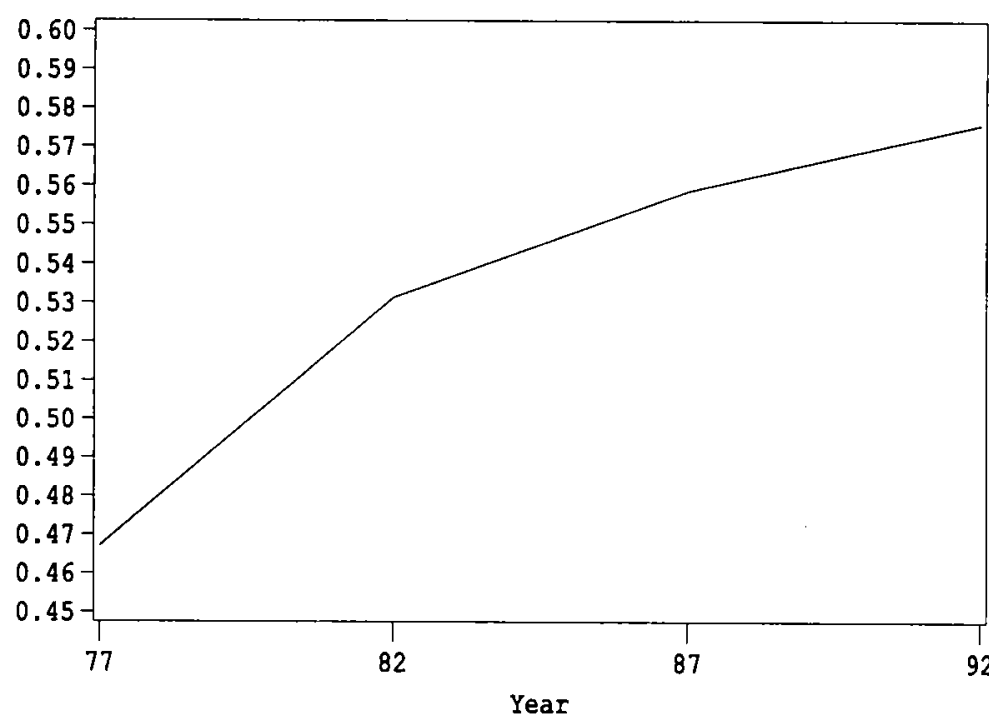

C. Observable Betas

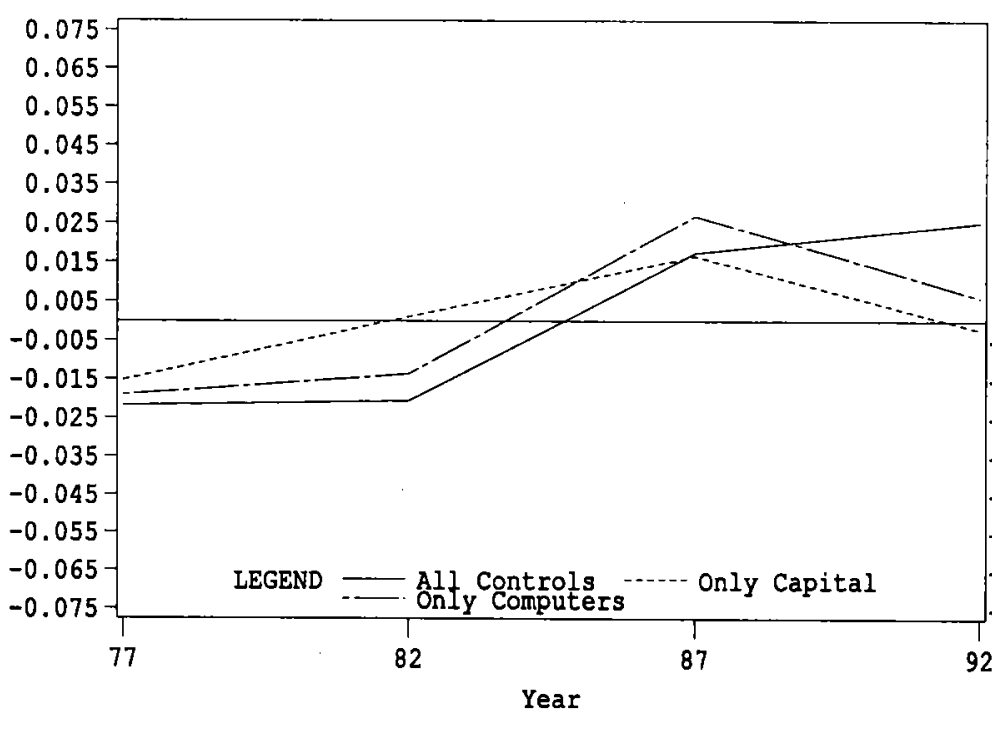

B. Observable Characteristics

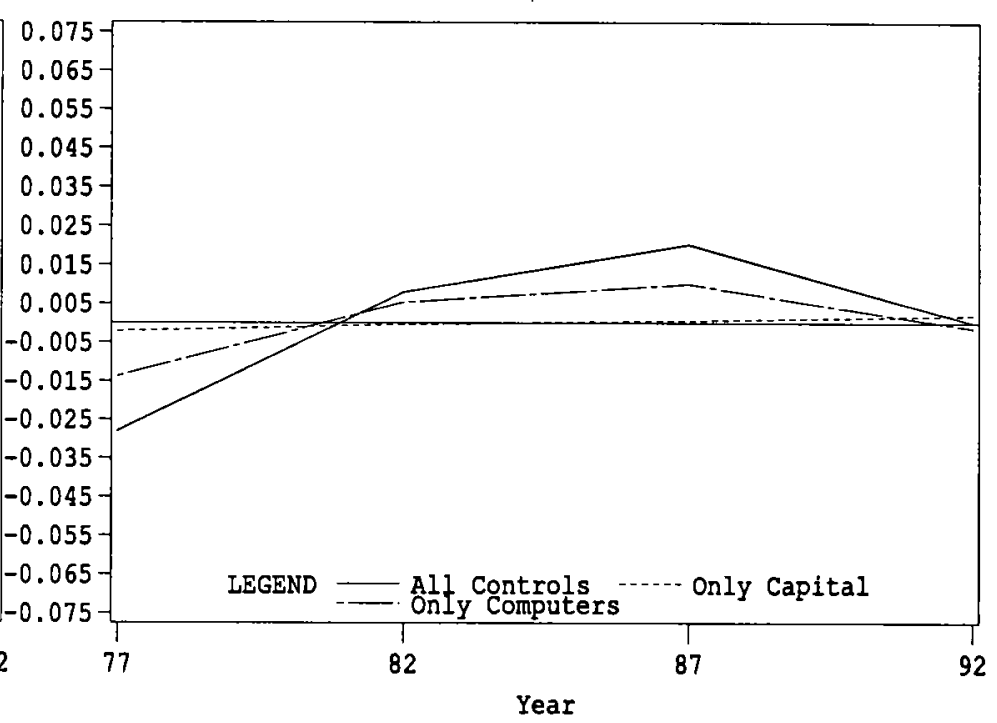

D. Unobservables

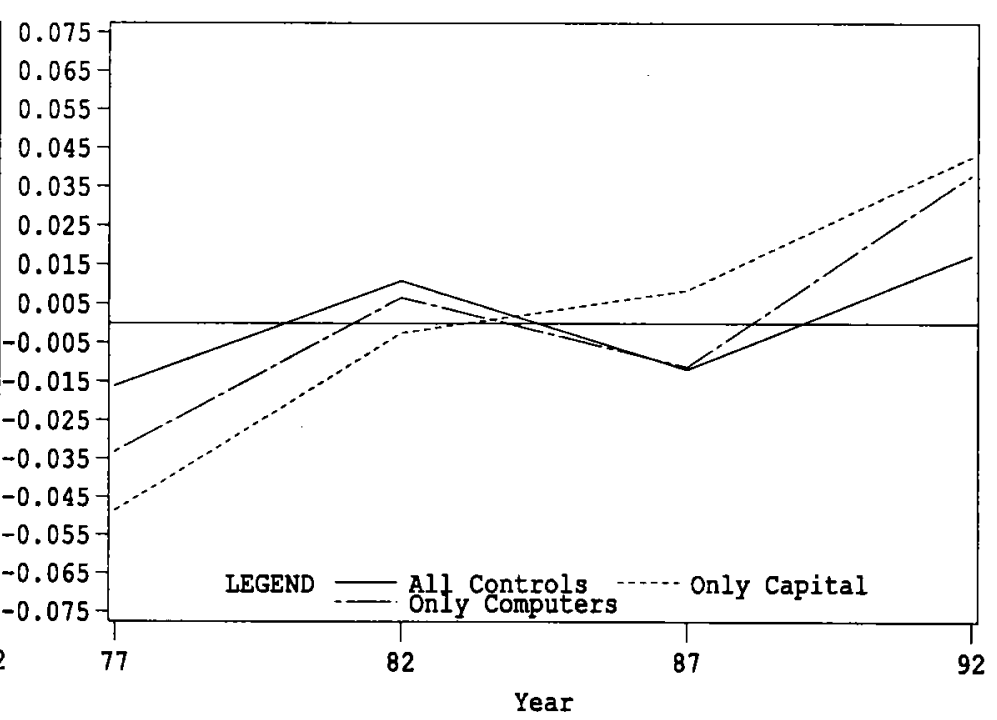

